This item was submitted to Loughborough's Research Repository by the author.

Items in Figshare are protected by copyright, with all rights reserved, unless otherwise indicated.

\title{
Photocatalytic mineralization and degradation kinetics of sulphamethoxazole and reactive red 194 over silver-zirconium co-doped titanium dioxide: Reaction mechanisms and phytotoxicity assessment
}

\section{PLEASE CITE THE PUBLISHED VERSION}

https://doi.org/10.1016/j.ecoenv.2018.04.062

\section{PUBLISHER}

Elsevier

\section{VERSION}

AM (Accepted Manuscript)

\section{PUBLISHER STATEMENT}

This work is made available according to the conditions of the Creative Commons Attribution-NonCommercialNoDerivatives 4.0 International (CC BY-NC-ND 4.0) licence. Full details of this licence are available at: https://creativecommons.org/licenses/by-nc-nd/4.0/

\section{LICENCE}

CC BY-NC-ND 4.0

\section{REPOSITORY RECORD}

Naraginti, Saraschandra, Yi Li, and Gianluca Li Puma. 2018. "Photocatalytic Mineralization and Degradation Kinetics of Sulphamethoxazole and Reactive Red 194 over Silver-zirconium Co-doped Titanium Dioxide: Reaction Mechanisms and Phytotoxicity Assessment". figshare. https://hdl.handle.net/2134/33516. 


\section{Graphical Abstract}

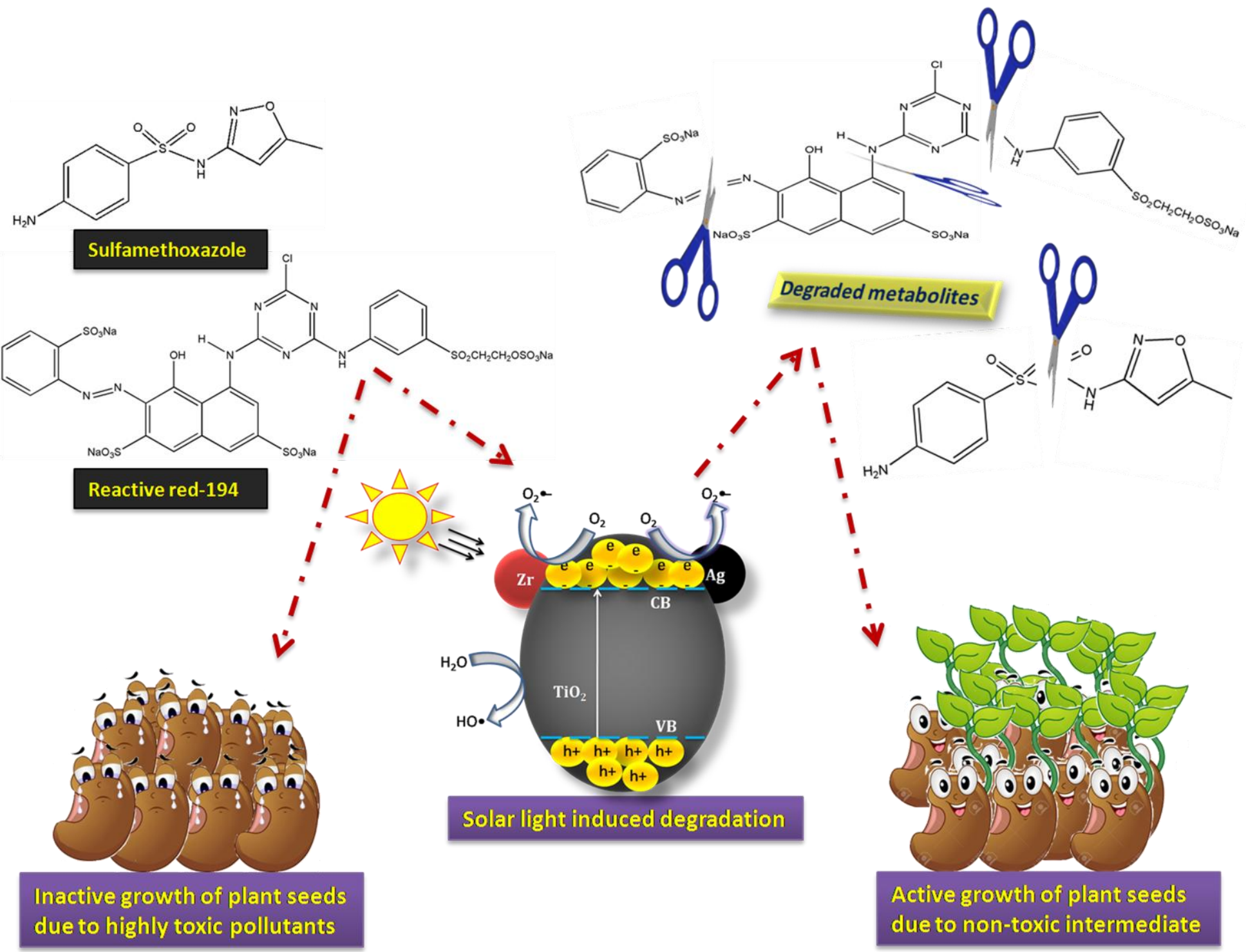

Inactive growth of plant seeds due to non-toxic intermediate 


\section{Highlights}

- $\mathrm{Zr}$ and $\mathrm{Ag}$ modified $\mathrm{TiO}_{2}$ composite was used for degradation of SMX and RR-194

- Mineralization pathway and phytotoxicity of degraded metabolites was evaluated

- Phytotoxicity tests revealed low-toxic intermediates were generated in degradation

- $\bullet \mathrm{OH}$ and $\bullet \mathrm{O}_{2}$ - radicals are found to be the main ROS on the photocatalyst surface 
1 Photocatalytic mineralization and degradation kinetics of sulphamethoxazole and reactive

17 Email: envly@hhu.edu.cn (Yi LI $)$

18 Email: g.lipuma@1boro.ac.uk (Gianluca LI PUMA)

7

9

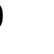

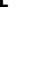

2

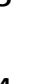

Corresponding authors

16
Ministry of Education, College of Environment, Hohai University, Nanjing - 210098, PR China
${ }^{\mathrm{c}}$ Environmental Nanocatalysis \& Photoreaction Engineering, Department of Chemical Engineering, Loughborough University, Loughborough LE11 3TU, United Kingdom

${ }^{a}$ Key Laboratory of Integrated Regulation and Resource Development on Shallow Lakes, red 194 over silver-zirconium co-doped titanium dioxide: Reaction mechanisms and phytotoxicity assessment

18

9

0

21

2

23 


\section{Abstract}

The photodegradation and phytotoxicity of the pharmaceutical antibiotic,

3

4 sulphamethoxazole (SMX) and the azo-dye reactive-red-194 (RR194) under visible-light irradiation of $\mathrm{TiO}_{2}$ nanoparticles modified by silver and zirconium was investigated. The results indicated that sulphamethoxazole and its toxic degradation by product, 3-amino-5methylisoxazole and RR-194 could be degraded efficiently by the co-doped $\mathrm{Zr} / \mathrm{Ag}-\mathrm{TiO}_{2}$ catalyst. PL studies and ROS generation results suggested that the effective charge separation was carried out while irradiation of the modified $\mathrm{TiO}_{2}$ nanoparticles. Phytotoxicity tests demonstrated lower percentage of germination in $P$. vulgaris (40\%), V. radiata (30\%) and P. lunatus $(30 \%)$ of the seeds treated with $50 \mathrm{ppm}$ of SMX, compared to the seeds treated with the degradation products (100\%). The results with $50 \mathrm{ppm}$ of RR-194 also showed lower percentage of germination in $P$. vulgaris (40\%), V. radiata (50\%) and P. lunatus (30\%) compared to the degradation products (100\%). Furthermore, significant increase in root and shoot development was observed in the seeds treated with the degraded products when compared with SMX and RR-194. Overall, this study contributes to further understanding the photodegradation mechanisms, degradation products and environmental fate of SMX and RR-194 in water which helps in the evaluation and mitigation of the environmental risk of SMX and RR-194 for water reuse and crop irrigation.

Keywords: Photocatalyst; Dyes; Antibiotics; Wastewater; Phytotoxicity 


\section{Introduction}

The extensive utilization of antibiotics in aquaculture, stockbreeding and human medicine have raised significant environmental concerns due to the observed increase in antibiotics resistant bacteria and genes [1-2]. In 2013, China consumed approximately 92,700 tons of antibiotics, 53,800 tons of which have been released into the environment [3]. Often these antibiotics have been detected in lakes, rivers, wastewater effluents [4], estuarine and coastal waters $[5,6]$. According to USEPA many antibiotics are reported as chemical contaminants of emerging concern, without much regulation and the effect on human health and the environment is inadequately understood [7].

Sulphonamides are belongs to a category of synthetic antibiotics prepared from sulphanilic acid which function as bacteriostatics by suppressing dihydrofolic acid generation. They have prolonged persistence in the environment due to their low degree of biodegradability. The concentration levels of these sulphonamides in water has been reported in the range of $0.13-$ $1.9 \mathrm{\mu LL}^{-1}$ [8], and could accumulate in several organisms such as bacteria $[9,10]$. Sulphamethoxazole belongs to a broad spectrum sulphonamide, and is one of the most extensively prescribed antibiotics worldwide. After administration, the metabolism of the content takes place in the liver, however the unmetabolized [11] and active metabolites [12,13] are then excreted in urine or feces ultimately reaching the gray water sewer systems and/or conventional wastewater treatment plants [14]. SMX is a refractory pollutant and not easily biodegraded by conventional treatments those employed in sewage treatment plants [15]. This necessitates the utilization of high efficiency materials and tertiary oxidative treatment for the effective degradation of SMX. In addition, the degradation products of SMX, such as 3-amino-5methylisoxazole, could cause a harmful threat to wildlife [16]. Studies have reported the 
70 formation of 3-amino-5-methylisoxazole during chemical [17-19] and microbial [20,21]

71 degradation of SMX, and fewer studies have reported its further transformation.

72 Other common classes of contaminants often found in water and wastewater are dyes

73 used in paints manufacturing and textiles. The azo dye RR-194 is a very common in cotton

74 dyeing. Azo dyes are highly carcinogenic, harmful to human health and cause reduced light

75 penetration in aqueous environments adversely affecting photosynthesis [22]. Conventional

76 methods including coagulation, activated-carbon adsorption, biodegradation and membrane

77 filtration have been used for wastewater decolorization. However, these methods cannot

78 completely remove the contaminants and their degradation products and often need further waste

79 disposal after treatment [23]. Thus, the treatment of dyes demands the development of new and

80 effective processes for their removal. Altogether, the untreated release of antibiotics, EDCs and

81 dye effluents would not only induce serious health and environmental hazards but also has a

82 strong impact on the fertility of soil.

Heterogeneous photocatalysis with visible light irradiation of modified titanium dioxide

$84\left(\mathrm{TiO}_{2}\right)$ nanoparticles has emerged one of the effective treatment methods for dyes and

85 pharmaceuticals removal [24-27] and for water reuse in agriculture. Co-doping of $\mathrm{TiO}_{2}$ with two

86 different atoms has attracted significant interest since the dual effect can synergistically affect

87 the photocatalytic activity of semiconductor materials compared to doping with a single element

$88[28,29]$. Addition of $\mathrm{Ag}$ and $\mathrm{Zr}$ can reduce the recombination of electrons and holes by efficient

89 trapping of electrons. Further, $\mathrm{Zr}$ is an isoelectric element exhibiting deep energy level doping 90 properties [30].

In this study $\mathrm{Ag}$ and $\mathrm{Zr}$ modified $\mathrm{TiO}_{2}$ nanoparticles have been utilized in the degradation

92 of SMX and RR-194. The possible degradation mechanisms were investigated by HPLC and LC- 
93 ESI/MS analysis. Water reuse necessitates the assessment of the phytotoxicity of the SMX, RR-

94194 and their corresponding degradation products. Therefore the phytotoxicity of the degradation

95 products and parent pollutants was investigated upon three plant seeds $P$. vulgaris, $V$. radiata

96 and $P$. lunatus to determine the environmental impact of the treated water.

97 2. Materials and methods

$98 \quad 2.1$ Materials

99

Titanium (IV) isopropoxide, terepthalic-acid (TA), nitroblue-tetrazolium-chloride (NBT)

100 and sulphamethoxazole (SMX) from Sigma, reactive red-194 from a local textile industry,

101 hydrazine hydrate, zirconyl nitrate $\left[\mathrm{ZrO}\left(\mathrm{NO}_{3}\right)_{2}\right]$, isopropanol, potassium iodide (KI), EDTA,

102 potassium dichromate $\left(\mathrm{K}_{2} \mathrm{Cr}_{2} \mathrm{O}_{7}\right)$, ascorbic acid, ethanol and tween-20 are purchased from

103 Alibaba Chemicals.

$104 \quad 2.2$ Synthesis and characterization of metal modified $\mathrm{TiO}_{2}$ nanoparticles

105 Metal modified $\mathrm{TiO}_{2}$ nanoparticles $\left(\mathrm{Ag} / \mathrm{TiO}{ }_{2}\right.$ and $\left.\mathrm{Zr} / \mathrm{Ag}-\mathrm{TiO}_{2}\right)$ were prepared according 106 to the methodology reported in our previous work [31]. BRUKER D8-Advance X-ray

107 diffractometer was used to obtain XRD data with $\mathrm{Cu} \operatorname{Ka}$ source $\left(\lambda=1.5406 \mathrm{~A}^{\circ}\right)$. Imaging of the 108 nanoparticles was carried out using a high resolution transmission electron microscope (JEOL 109 JEM 2100). UV-Vis spectra (DRS mode) were recorded on a JASCO V-670 UV-Vis 110 spectrophotometer. The photoluminescence (PL) spectra were obtained on a HITACHI F-7000 111 fluorescence spectrophotometer. XPS data was acquired on a Kratos Axis Ultra 165 112 Spectrometer equipped with a monochromated Al Ka X-ray source $(\mathrm{h} \alpha=1486.6 \mathrm{eV})$. A 113 micrometrics ASAP 2020 V4.03 analyzer was used to obtain BET surface area and pores size 114 distributions of the synthesized nanoparticles. The zeta potentials of $\mathrm{TiO}_{2}, \mathrm{Ag} / \mathrm{TiO} 2$ and $\mathrm{Zr} / \mathrm{Ag}-$ 
$115 \mathrm{TiO}_{2}$ nanoparticles were measured at $25{ }^{\circ} \mathrm{C}$ by dynamic laser light scattering using Malvern Zetasizer Nano ZS90.

\subsection{Degradation experiments and determination of by products}

A laboratory scale photoreactor (Fig. 1), was designed and utilized for all photocatalytic degradation experiments, which consists of a visible light source (Osram $150 \mathrm{~W}$ tungsten halogen lamp with $100 \mathrm{~mW} / \mathrm{cm}^{2}$ intensity, $\lambda: 400-800 \mathrm{~nm}$ ) positioned at the center of the reactor. Six reaction tubes, $50 \mathrm{ml}$ each, $10 \mathrm{~mm}$ internal diameter, were placed at a distance of $15 \mathrm{~cm}$ from the light source. Dry air was purged continuously into all the reaction tubes through small pipes at a flowrate of $2 \mathrm{~L} \mathrm{~min}^{-1}$, to keep the aqueous solution saturated with oxygen and the catalyst particles in suspension. The inner surface of the photoreactor hood was fitted with a highly

125 polished reflector in order to ensure the maximum reflection and utilization of the light source. The bottom of the reactor was equipped with an electric fan to cool the cabinet during the

127 experiments maintaining a constant temperature $\left(25 \pm 2{ }^{\circ} \mathrm{C}\right)$.
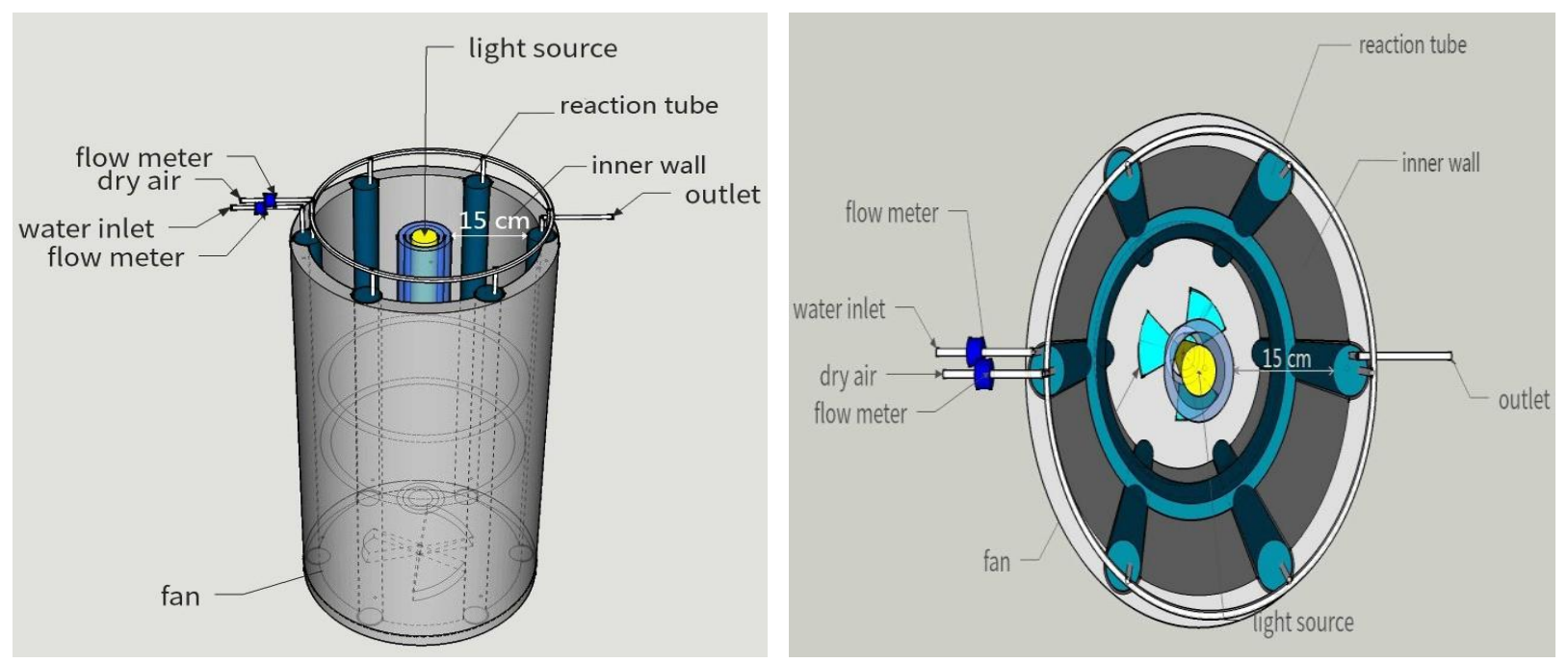

equipped with an Eclipse XDBC18 $(4.6$ x $150 \mathrm{~mm}, 5 \mu \mathrm{m})$ reverse phase column. Initially 100 $\mathrm{mL}$ of SMX solution $(20 \mathrm{ppm})$ and $50 \mathrm{mg}$ of the catalyst were stirred in the dark for $60 \mathrm{~min}$ to 141 obtain absorption-desorption equilibrium, [32,33]. The UV detector wavelength was $203 \mathrm{~nm}$, 142 while the mobile phase consisted of water and acetonitrile (70:30 v/v) fed at a flow rate of $1 \mathrm{~mL}$ $143 \min ^{-1}$ for 60 minutes [34]. Similar procedure was followed to achieve absorption-desorption 144 equilibrium during degradation of RR-194 (25 ppm), as discussed above. Small sample aliquots 145 (2 mL) were collected at regular time intervals and the solids were separated through 146 centrifugation at $2000 \mathrm{rpm}$ for $5 \mathrm{~min}$. The supernatants were analyzed by a JASCO V-670 UV147 Vis spectrophotometer, recording the absorption at $522 \mathrm{~nm}$.

148 Further, the analysis of SMX and RR-194 degradation products was carried by liquid 149 chromatography tandem mass spectrometer (Agilent 1290 LC system, Agilent 6460 Triple 150 Quadrupole LCMS/MS system with the Zorbax eclipse plus C18 column). Water and acetonitrile $151(70: 30 \mathrm{v} / \mathrm{v})$ as mobile phase at a flow rate of $0.2 \mathrm{~mL} \mathrm{~min}^{-1}$ was used for SMX analysis (60 min 152 of run time), while methanol and water (30:70 v/v) was used for the analysis of RR-194 (60 min 153 of run time). Spray Ionization (ESI) under the flow of helium gas $\left(1 \mathrm{~mL} \mathrm{~min}{ }^{-1}\right)$ was used to 154 obtain mass spectra at a fragment voltage of $16 \mathrm{~V}$.

\section{$155 \quad 2.4$ Active species scavenging experiments}

To investigate the main reactive oxygen species (ROS), various scavenging experiments

157 were conducted during the photocatalytic degradation processes. These were performed by 158 adding ascorbic acid for $\mathrm{O}_{2}^{\bullet}-$ scavenging [35], EDTA for $\mathrm{h}^{+}$scavenging [36], $\mathrm{K}_{2} \mathrm{Cr}_{2} \mathrm{O}_{7}$ for $\mathrm{e}^{-}$ 159 scavenging [37], isopropanol for $\bullet \mathrm{OH}$ scavenging [38], and $\mathrm{KI}$ for both $\bullet \mathrm{OH}$ and $\mathrm{h}^{+}$scavenging $160[35,36]$ during the photocatalytic reactions. For quantification of $\bullet \mathrm{OH}$, the photocatalyst $(50 \mathrm{mg})$ 
161 was added to a $50 \mathrm{ml}$ mixture of TA $(3 \mathrm{mmol})$ and $\mathrm{NaOH}(10 \mathrm{mmol})$ aqueous solution. Thus, TA

162 quickly reacts with generated $\cdot \mathrm{OH}$ radicals to form a fluorescent active 2-hydroxyterephthalic

163 acid (TAOH) which emits fluorescence at $426 \mathrm{~nm}$ on excitation at $312 \mathrm{~nm}$ (Scheme 2). The

164 amount of $\bullet \mathrm{OH}$ radicals generated during irradiation should be directly proportional to the

165 photoluminescent intensity of TAOH. Similarly, the quantification of $\bullet \mathrm{O}_{2}-$ radicals was carried

166 out by monitoring $\operatorname{NBT}\left(2 \times 10^{-4} \mathrm{M}\right)$ absorption peak at $259 \mathrm{~nm}$. Upon reaction with $\cdot \mathrm{O}_{2}^{-}$

167 radicals NBT can be peculiarly reduces to form an insoluble purple formazan compounds in the

168 aqueous solutions (Scheme 1). The quantification of $\bullet \mathrm{O}_{2}^{-}$was done by analyzing the decrease in

169 the NBT concentration using a UV-Vis spectrophotometer.

$170 \quad 2.5$ Phytotoxicity Assessment

171 The phytotoxicity assessment test of toxicants and their corresponding metabolites was

172 carried out on three types of crop seeds, $P$. vulgaris, V. radiata and $P$. lunatus, using 50 ppm

173 concentration of SMX, RR-194 and with the irradiated samples containing the reaction

174 degradation products. The degraded metabolites of SMX and RR-194 were extracted by ethyl

175 acetate then dried and dissolved in $10 \mathrm{~mL}$ distilled water to obtain a final concentration of 50

176 ppm. The phytotoxicity test was carried out by following the prescribed guidelines in the

177 literature $[39,40]$ with few modifications. Seeds of each crop type (10 no) were sterilized using 1-

$1785 \%$ sodium hypochlorite solution $(15 \mathrm{~min})$ followed by thorough washing with distilled water.

179 They were then immersed for $60 \mathrm{~min}$ in the SMX, RR-194 aqueous solutions and in the samples

180 subjected to photocatalytic degradation using $100 \mathrm{~mL}$ Erlenmeyer flasks containing the

181 contaminants and their respective degradation products. Seeds immersed in distilled water were

182 used as controls for comparison. The seeds were then placed on a wet cotton in different petri 
183 dishes and incubated at $25 \pm 1^{\circ} \mathrm{C}$ in dark $(24 \mathrm{~h})$. The germinated seeds were selected for further 184 toxicity studies.

Further phytotoxicity assays were continued in beakers containing $1.5 \%$ agar media (30 $\mathrm{mL})$ and $50 \mathrm{ppm}$ of SMX, RR-194 and the reaction degradation products. The agar containing

187 beakers were instantly hardened in a freezer. Germinated seeds from the petri plates were placed 188 on the surface of the agar in each beaker and then placed in incubator at $25 \pm 1^{\circ} \mathrm{C}$ in dark. 189 Control experiments were included with seedlings on agar alone without the contaminants. After 1905 days of incubation the plants were slowly removed from the agar media and lengths of the root 191 and shoots were measured. The experiments were carried out in triplicate and the average data 192 was shown in the present study.

\section{Results and discussion}

\section{$195 \quad 3.1$ Characterization}

Fig. S1a shows the UV-Vis absorption spectra of synthesized bare $\mathrm{TiO}_{2}, \mathrm{Ag} / \mathrm{TiO}_{2}$ and $197 \mathrm{Zr} / \mathrm{Ag}-\mathrm{TiO}_{2}$ respectively. Red shifts were observed as a result of the incorporation of silver and 198 zirconium into $\mathrm{TiO}_{2}$ matrix in both $\mathrm{Ag} / \mathrm{TiO}_{2}$ (absorption edge shift from 340 to 380) and $\mathrm{Zr} / \mathrm{Ag}-$ $199 \mathrm{TiO}_{2}$ (maximum red shift from $380 \mathrm{~nm}$ to $400 \mathrm{~nm}$ ). The red shifted spectra show a possible 200 evidence for good interaction between $\mathrm{TiO}_{2}, \mathrm{Ag}$ and $\mathrm{Zr}$ species. Hence, the observed red shift 201 behavior clearly justifies the change in the light absorption characteristics. The energy band gap 202 values (Fig.S1b) of bare $\mathrm{TiO}_{2}, \mathrm{Ag} / \mathrm{TiO}$ and $\mathrm{Zr} / \mathrm{Ag}-\mathrm{TiO}_{2}$ were calculated to be around $3.18 \mathrm{eV}$, $203 \quad 3.08 \mathrm{eV}$ and $2.87 \mathrm{eV}$, respectively. These results suggest that the $\mathrm{Zr} / \mathrm{Ag}-\mathrm{TiO}_{2}$ nanoparticles could 204 possibly show a higher photocatalytic activity in the visible region. 

displayed diffraction peaks corresponding to the $\mathrm{TiO}_{2}$ anatase (JCPDS 21-1272) crystalline phase. Because of their low concentration levels (0.2-0.8 mole \%), peaks related to metallic $\mathrm{Zr}$ or Ag were not observed in the XRD pattern, which suggested that dopants did not alter the crystallinity of $\mathrm{TiO}_{2}$. Furthermore, the representing oxide compounds $\left(\mathrm{Zr}_{\mathrm{x}} \mathrm{O}_{\mathrm{y}}\right.$ or $\left.\mathrm{Ag}_{\mathrm{x}} \mathrm{O}_{\mathrm{y}}\right)$ were not

211 found either, suggesting that nano $\mathrm{Zr}$ and $\mathrm{Ag}$ particles were well diffused into the $\mathrm{TiO}_{2}$ crystal

212 lattice, thus enhancing the visible light absorption.
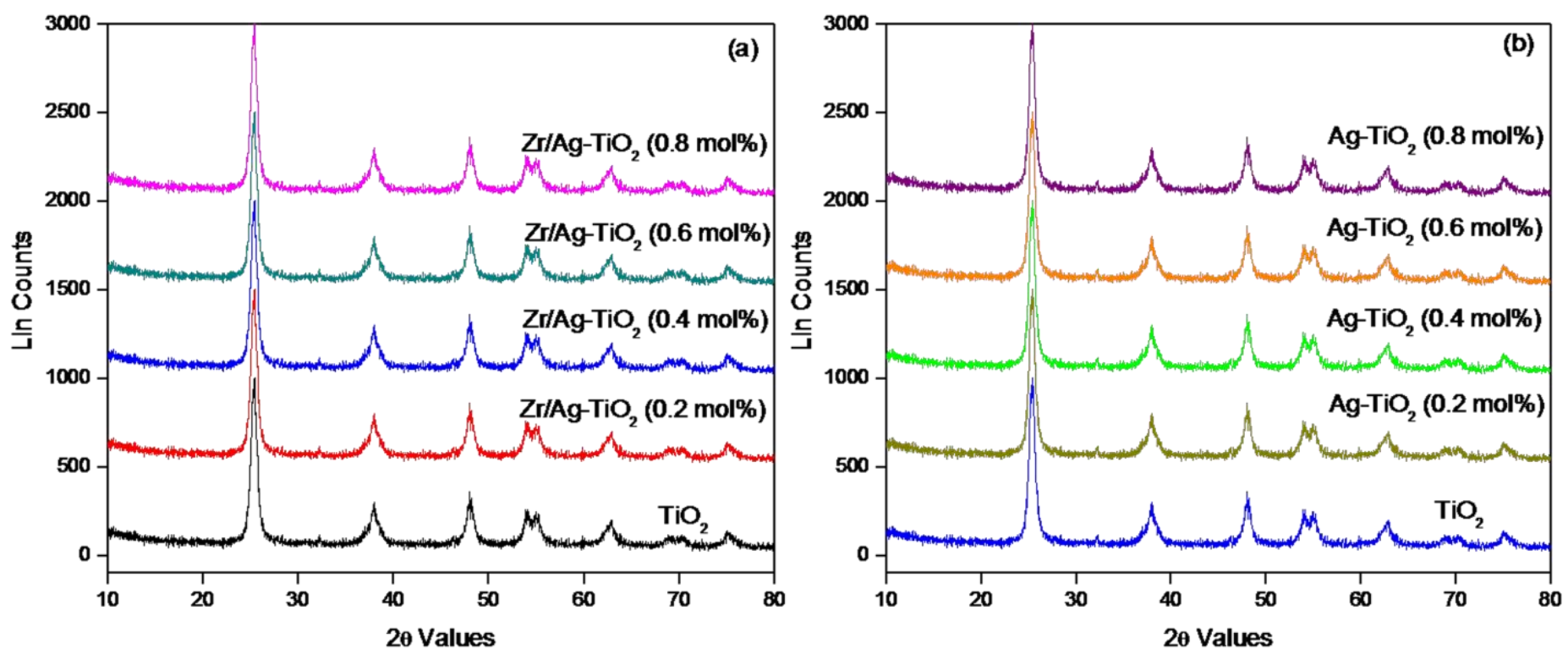

Fig. 2 X-ray diff raction pattern of the synthesized nanoparticles

TEM images of $\mathrm{Ag} / \mathrm{TiO}_{2}$ and $\mathrm{Zr} / \mathrm{Ag}-\mathrm{TiO}_{2}$ (Fig. S2a and S3a) suggested uniform

217 distribution of the particles ranging from 10-17 $\mathrm{nm}$ and 7-15 $\mathrm{nm}$ respectively. High resolution 218 TEM pictures were (Fig. S2b and S3b) employed to observe the microstructure of the 219 photocatalysts, for analyzing the particle grains and their boundaries. The SAED patterns of the 220 prepared nanoparticles (Fig. S2c and S3c) clearly showed dark fringes corresponding to the 221 standard diffraction rings of the polycrystalline anatase phase as indexed. Diffraction fringes 
222 signals related to other phases were not found. The EDAX profile (Fig. S2d and S3d) evidenced 223 the elemental composition of the prepared samples.

225 are shown in Fig. S3. From the results it was found that the pHzpc of $\mathrm{TiO}_{2}, \mathrm{Ag}-\mathrm{TiO}_{2}$ and $\mathrm{Zr} / \mathrm{Ag}-$

$226 \mathrm{TiO}_{2}$ is $6.38,6.13$ and 6.09 respectively. At lower $\mathrm{pH}$ levels the photocatalyst surface becomes

227 more positive at $\mathrm{pH}$ below $\mathrm{pHzpc}$ and more negative above it [41,42]. With increase in negative 228 zeta potential values, the stability of the catalyst increases at higher $\mathrm{pH}$ levels. From the results it 229 reveals that $\mathrm{Zr} / \mathrm{Ag}-\mathrm{TiO}_{2}$ particles shown relatively better stability at higher $\mathrm{pH}$. The relative zeta230 potential values were from 18.8 to $27.9 \mathrm{mV}$ at $\mathrm{pH}$ 9, while it was altered between 5.8 to $15.1 \mathrm{mV}$ 231 at $\mathrm{pH}$ 3. It indicates that, at lower $\mathrm{pH}$ levels the metal modified $\mathrm{TiO}_{2}$ nanoparticles defended 232 destabilization, and the zeta-potential values of did not increase majorly at $\mathrm{pH}<\mathrm{pHzpc}$ than over 233 pHzpc [43].

The evident XPS spectra for $\mathrm{Ag} 3 \mathrm{~d}, \mathrm{Zr} 3 \mathrm{~d}$, Ti 2p and O 1s levels were carried out to 235 analyze whether the doped metals interwove into $\mathrm{TiO}_{2}$ crystal lattice or formed surface 236 compounds. The relevant high-resolution XPS spectrum of Ag at 3d core levels shown in Fig. 3a 237 indicates that the binding energies for $\mathrm{Ag} 3 \mathrm{~d}_{5 / 2}$ and $\mathrm{Ag} 3 \mathrm{~d}_{3 / 2}$ are observed at 368.1 and $374.1 \mathrm{eV}$ 238 which matches with the bulk metallic silver $[44,45]$. The binding energies for $\mathrm{Zr} 3 \mathrm{~d}_{5 / 2}$ and $\mathrm{Zr}$ $2393 \mathrm{~d}_{3 / 2}$ observed at 182.4 and $184.6 \mathrm{eV}$ (Fig. $3 \mathrm{~b}$ ), are attributed to the +4 oxidation state of 240 zirconium [46]. XPS spectrum of Ti 2p (Fig. 3c) shown peaks at 459.2 and $464.9 \mathrm{eV}$ were 241 belongs to $\mathrm{Ti} 2 \mathrm{p}_{3 / 2}$ and $\mathrm{Ti} 2 \mathrm{p}_{1 / 2}$ core levels respectively $[47,48]$. These results designate that 242 titanium represent +4 oxidation state. Fig. 3d shows the broad spectrum of $\mathrm{Zr} / \mathrm{Ag}-\mathrm{TiO}_{2}$ 243 nanocomposite, indicates that in $\mathrm{Zr} / \mathrm{Ag}-\mathrm{TiO}_{2} \mathrm{Ag}$, $\mathrm{Ti}$ and $\mathrm{Zr}$ metal ions were present in their 244 highest oxidation state. 

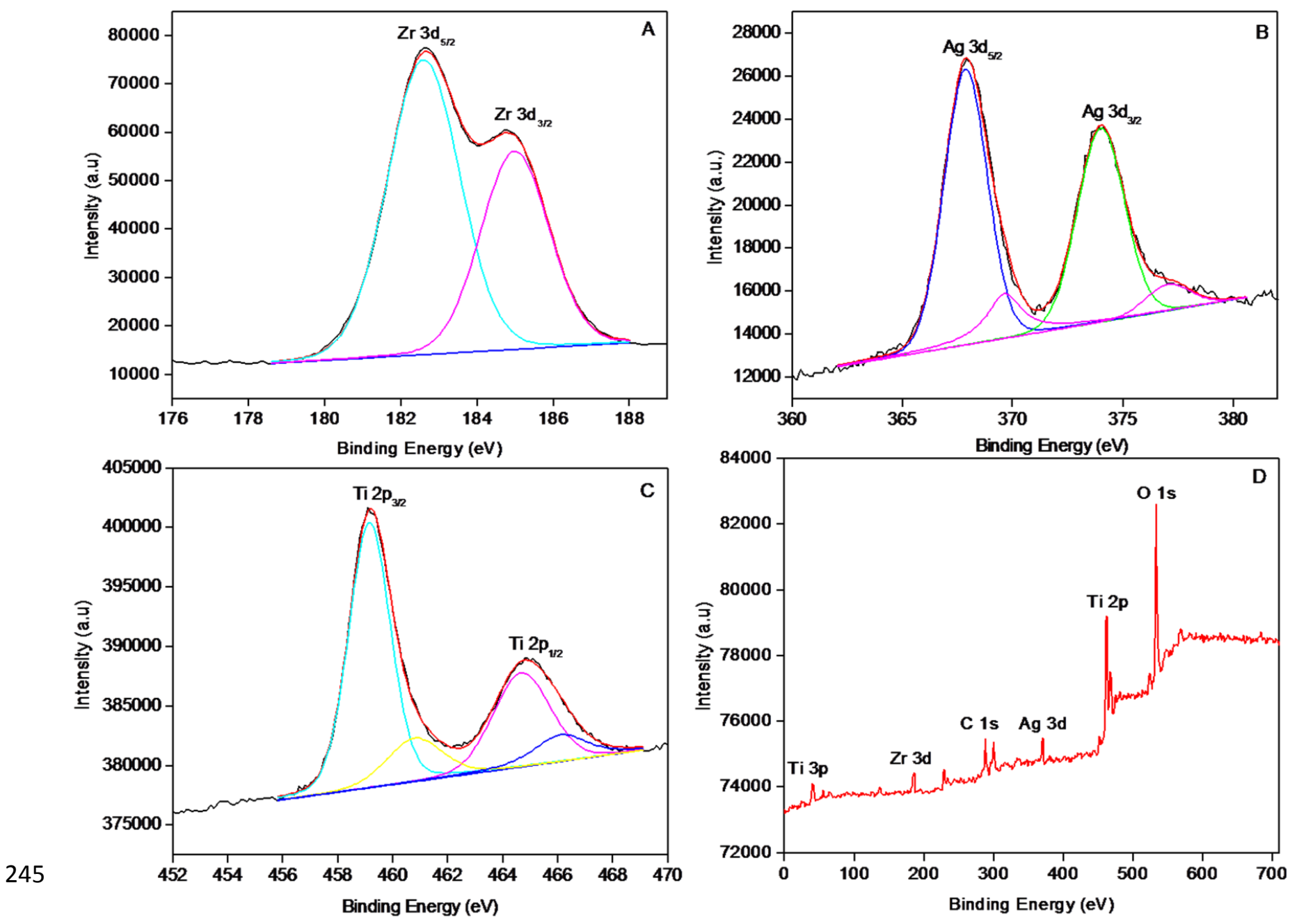

247 Fig. 3 High resolution XPS spectrum of (a) Ag at 3d, (b) Zr at 3d, (c) Ti at 2p core levels and (d)

248 broad spectrum of $\mathrm{Zr} / \mathrm{Ag}-\mathrm{TiO} 2$ nanocomposite

249 The production of $\bullet \mathrm{O}_{2}^{-}$radical during the photocatalytic process was determined by the

250 NBT transformation method [49] (Scheme 1). Fig. S8 b showed the kinetic NBT transformation

251 percentage at different time intervals during irradiation. The higher generation rates of $\bullet \mathrm{O}_{2}{ }^{-}(\mathrm{Fig}$.

252 S7b) with increase in irradiation time could be ascribed to the lower energy band gap of $\mathrm{Zr} / \mathrm{Ag}-$

$253 \mathrm{TiO}_{2}$ and lower rate of photogenerated electron-hole recombination as shown by the PL spectra.

254 The generated photo electrons remaining in the conduction band $(\mathrm{CB})$ during the photoexcitation 
255 of the semiconductor photocatalyst, reacted with adsorbed $\mathrm{O}_{2}$ molecules to generate highly 256 reactive $\cdot \mathrm{O}_{2}{ }^{-}$. Since the energy band gap of $\mathrm{Zr} / \mathrm{Ag}-\mathrm{TiO}_{2}$ was the smallest, the photogenerated

257 electrons from the valence band (VB) could be easily transferred to the CB with more effective 258 charge separation and reduced electron-hole pair recombination. This eventually led to higher 259 decomposition of SMX and RR-194, which was further supported by the active scavenging 260 experiment results (Fig. S7).

Quantification of $\bullet \mathrm{OH}$ radicals during photocatalytic process was carried out by using 262 terephthalic-acid photoluminescence probe method (TA-PL). Terephthalic-acid readily reacts 263 with the produced $\bullet \mathrm{OH}$ radicals and forms a highly fluorescent 2-hydroxyterephthalic acid 264 (TAOH) [50-52] (Scheme 2). The rate of formation of $\mathrm{TAOH}$ with pure $\mathrm{TiO}_{2}$ was negligible 265 consistent with its large band gap. In contrast, the formation of TAOH was significant with $266 \mathrm{Zr} / \mathrm{Ag}-\mathrm{TiO}_{2}$ nanoparticles showing the higher rate, as expected consistent with its smaller band 267 gap (Fig. S8a). The above results indicated that $\bullet \mathrm{O}_{2}^{-}$and $\bullet \mathrm{OH}$ radicals played a major role in the 268 degradation of both SMX and RR-194 under visible light.

269 3.2 Degradation kinetics and pathway of SMX and RR-194

270 Langmuir-Hinshelwood model (Eq.1) was used to describe the photodegradation kinetics 271 of SMX and RR-194 under visible light (Eq.1), which illustrates that the reactions take place at a 272 solid-liquid interface. 
278 to indicate that $\mathrm{Zr} / \mathrm{Ag}-\mathrm{TiO}_{2}$ nanocomposite had more than 1.5 times better degradation efficiency 279 in degrading SMX compared to the other visible light photocatalyst (e.g., $\mathrm{Cu}-\mathrm{TiO}_{2}$ nanoparticles [53]).
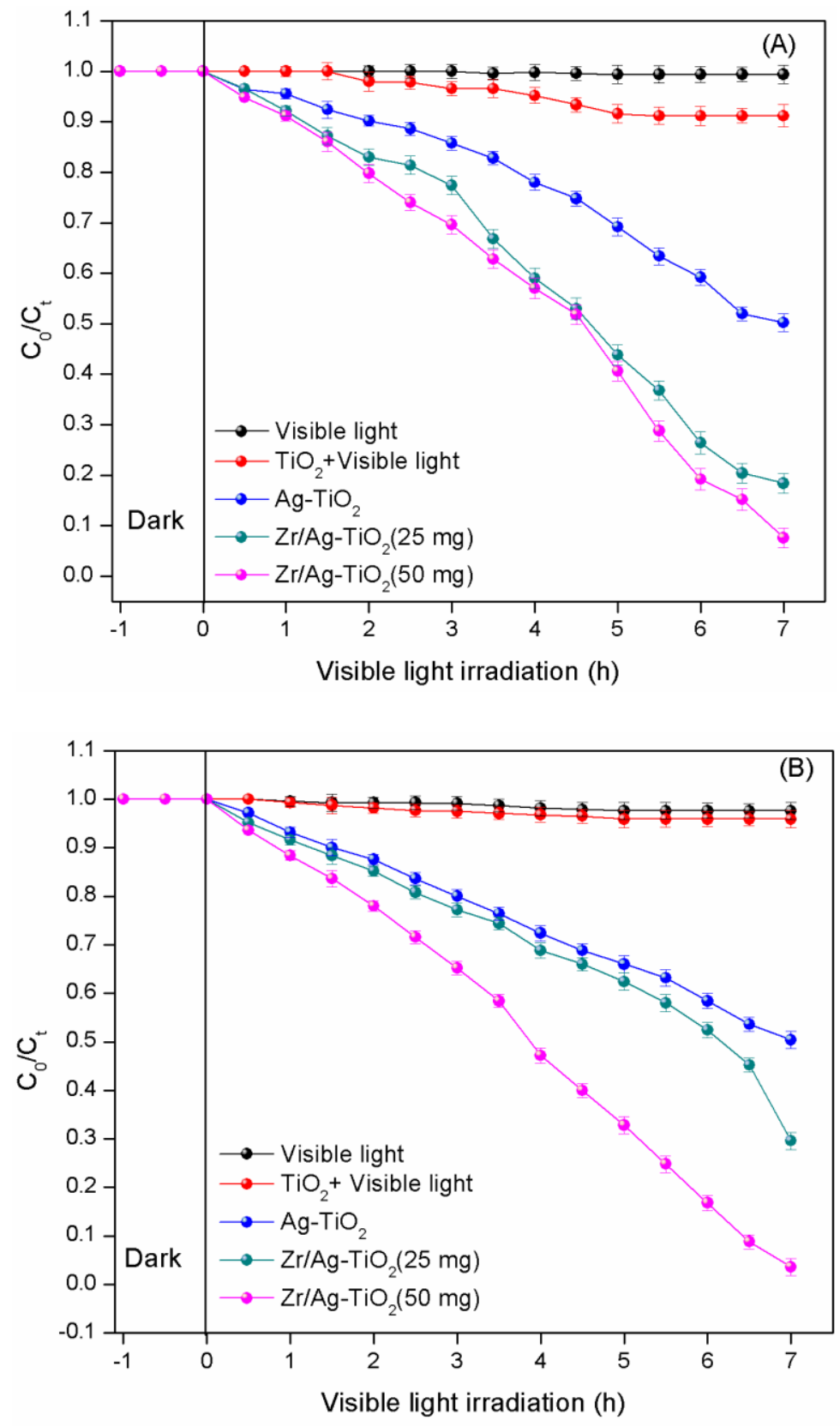

Fig. 4 Kinetic curves of SMX (a) and RR-194 (b) degradation suing different photocatalysts under visible light 
LC-ESI/MS analysis of the sampled before and after irradiation was performed to 287 elucidate the reaction mechanisms of photocatalytic degradation of SMX and RR-194 over 288 visible light irradiated $\mathrm{Zr} / \mathrm{Ag}-\mathrm{TiO}_{2}$ nanoparticles. LC-MS analysis of the SMX degraded samples 289 evidenced the presence of compounds with molecular weights $252.2(\mathrm{M}+3), 238.2(\mathrm{M}+2), 226.2$ 290 (M-2), 186.2 (M-3) and 184.2 (M-1) which could be interpreted as structures A, B, C, D and G 291 (Fig. 5 \& S5). The byproduct L was identified as 3-amino-5-methylisoxazole (3A5MI) with m/z $292=99.9$ for $[\mathrm{M}-1]^{+}$which results from the cleavage of the $\delta$-position and further oxidation by $293 \cdot \mathrm{OH}$. The byproduct $\mathrm{F}$ was identified as sulfanilamide $\left(\mathrm{C}_{6} \mathrm{H}_{8} \mathrm{~N}_{2} \mathrm{O}_{2} \mathrm{~S}\right)$ as a result of $\gamma$-cleavage, the 294 important intermediate during SMX degradation. The degraded product of SMX also showed $295 \mathrm{~m} / \mathrm{z}$ values of $213(\mathrm{M}+1), 199.9(\mathrm{M}+1), 106.9(\mathrm{M}+1), 145.9(\mathrm{M}-4), 160.9(\mathrm{M}-4), 174.9(\mathrm{M}-3)$ 296 and 117.9 (M-2) which represents the structures E, F, K, J, I, H and M (Fig. 5 \& S5). The 297 fragment ion corresponds to $\mathrm{m} / \mathrm{z} 157.1$ suggests that the SMX degradation initiates by attacking 298 the $\cdot \mathrm{OH}$ radicals on the isoxazole ring. Nonselective attack by $\bullet \mathrm{OH}$ on SMX molecule at various 299 sites is the first oxidation step of SMX, this results in the establishment of hydroxylated 300 derivatives, which are further oxidized by $\bullet \mathrm{OH}$ to form additional byproducts. The structures $\mathrm{J}$ 301 and L were identified as maleic acid and cyclohexa-2,5-diene-1,4-dione, which could finally lead 302 to formation of $\mathrm{H}_{2} \mathrm{O}$ and $\mathrm{CO}_{2}$ [54].

303 The LC-MS/MS pattern of the RR-194 degraded sample also showed the presence of 304 different compounds with $\mathrm{m} / \mathrm{z}$ values of $753.2(\mathrm{M}+1), 679.2(\mathrm{M}+3), 632.6(\mathrm{M}-4), 527(\mathrm{M}+3)$, $305511.1(\mathrm{M}+3)$ and 453.1 (M-2) which could be interpreted structures A, B, C, D, E and F (Fig. 6 306 \& S6). The RR-194 degraded sample also showed peaks with m/z values of 385.8 (M-), 340.1 307 (M+4), 327.7(M+2), 309.7 (M-3), $287.7(\mathrm{M}-3), 223.8(\mathrm{M}-3), 193.8(\mathrm{M}+2), 178.8(\mathrm{M}+2), 129.9$ 

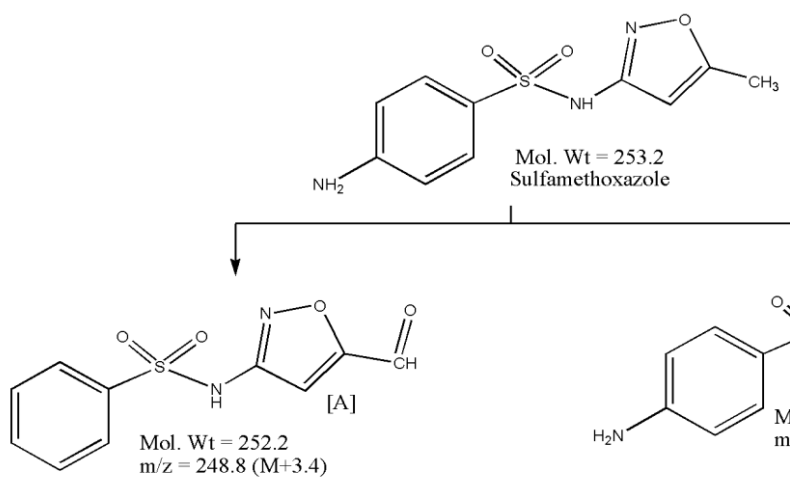
Sulfamethoxazole
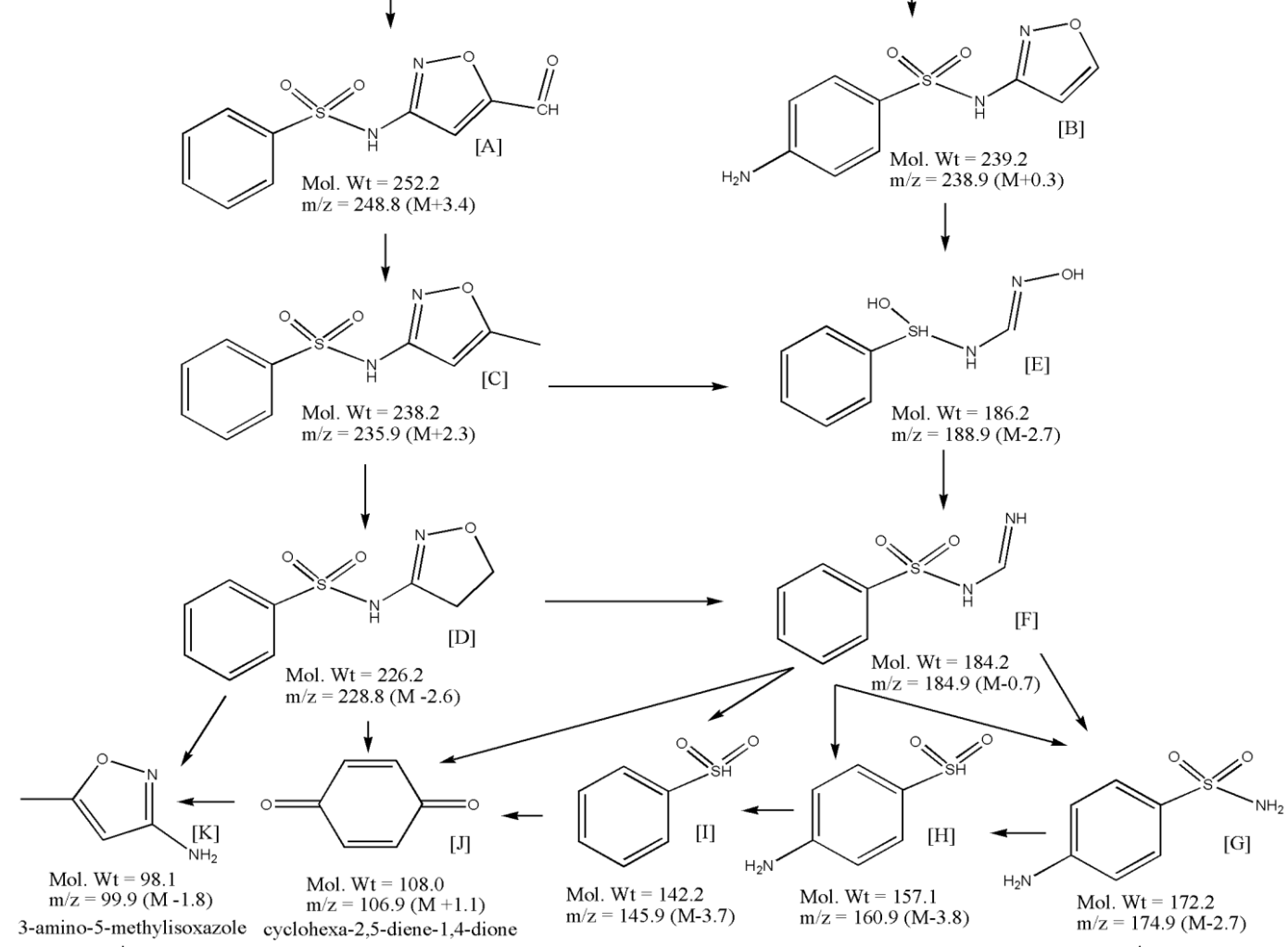

3-amino-5-methylisoxazole cyclohexa-2,5-diene-1,4-dione

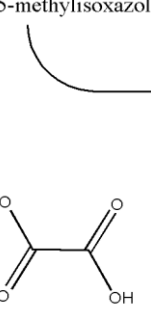

Oxalic acid
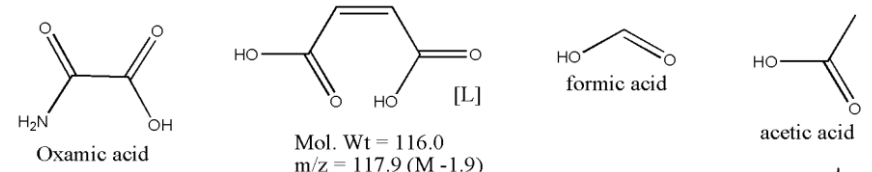

Mol. Wt $=116.0$

$\mathrm{m} / \mathrm{z}=117.9(\mathrm{M}-1.9)$

acetic acid

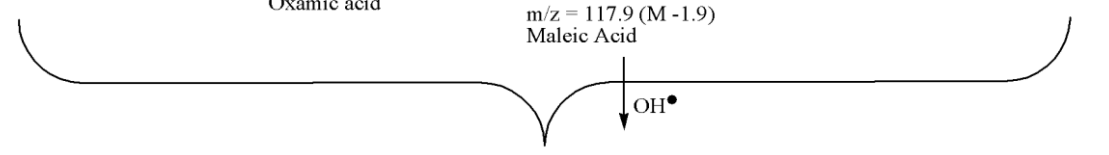

$\mathrm{CO}_{2}, \mathrm{H}_{2} \mathrm{O}$ and inorganic ions

329 Fig. 5 Transformation pathway of SMX by Zr/Ag-463 TiO2 (50 mg) nanocomposite under visible light 


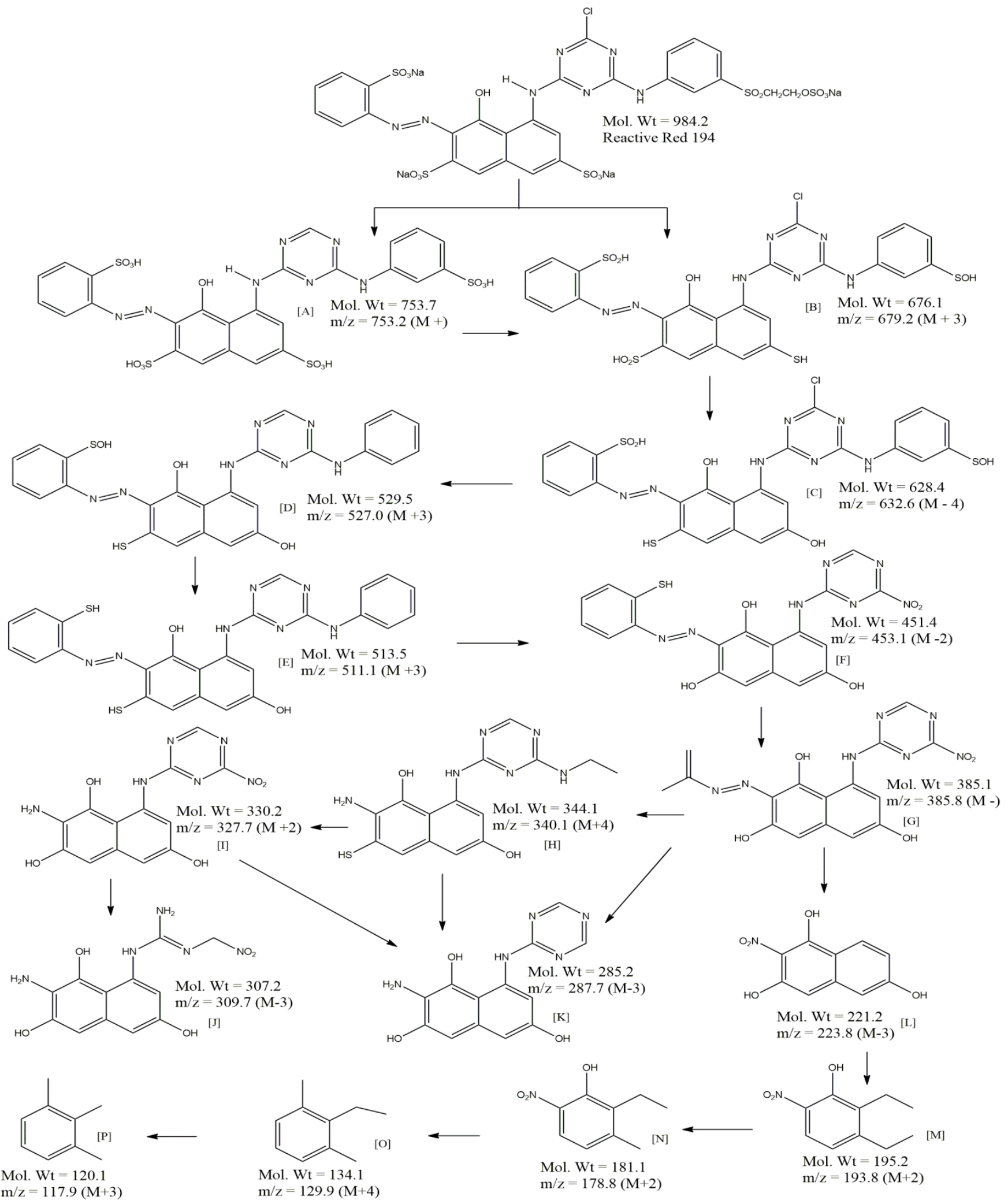

Fig. 6 Transformation pathway of RR-194 by Zr/Ag-TiO2 (50 mg) nanocomposite under visible

333 light 


\subsection{Active species scavenging experiment}

Different scavenging experiments were carried out in order to investigate the main radical species involved in the photocatalytic degradation of SMX and RR-194 under visible light irradiation. Ascorbic acid, EDTA, $\mathrm{K}_{2} \mathrm{Cr}_{2} \mathrm{O}_{7}$ and isopropylalcohol were used as $\bullet \mathrm{O}_{2}{ }^{-}, \mathrm{h}^{+}$, $\mathrm{e}^{-}$, and - $\mathrm{OH}$ scavengers, while potassium iodide (KI) was used as scavenger for both $\bullet \mathrm{OH}$ and $\mathrm{h}^{+}$(Fig. S7 a \& b). By adding scavengers to the reaction solution the decreased photocatalytic activity was in the following order: isopropanol $>$ ascorbic acid $>$ EDTA $>$ potassium iodide $>$ potassium dichromate > no scavenger. In the $\mathrm{N}_{2}$ saturated solution, SMX and RR-194 degradation over $\mathrm{Zr} / \mathrm{Ag}-\mathrm{TiO}_{2}$ was significantly inhibited. Thus, these findings proposed that the degradation of SMX and RR-194 was most interfered by adding isopropyl alcohol and ascorbic acids to the reaction solution, confirms that the $\bullet \mathrm{OH}$ and $\bullet \mathrm{O}_{2}{ }^{-}$radicals were the main reactive oxygen species (ROS) during the photodegradation processes. Moreover, the addition of EDTA and $\mathrm{K}_{2} \mathrm{Cr}_{2} \mathrm{O}_{7}$ demonstrated minimal decrease in the photoctalytic degradation process compared to isopropyl alcohol and ascorbic acid, which incriminate that the $\bullet \mathrm{OH}$ and $\bullet \mathrm{O}_{2}{ }^{-}$were the primary ROS responsible for the effective degradation of the contaminants.

\subsection{Phytotoxicity}

SMX (50 ppm) highly inhibited the germination of $P$. vulgaris, V. radiata and P. lunatus, reducing it to $40 \%, 30 \%$ and $30 \%$ respectively. Less germination was also found in all three seeds $P$. vulgaris $(40 \%), V$. radiata $(50 \%)$ and $P$. lunatus $(30 \%)$ treated with RR-194. However, the seeds treated in $50 \mathrm{ppm}$ of the photodegradion products and distilled water (control) exhibited $100 \%$ germination (Table 1). Furthermore, the toxicity of pure SMX solutions is also reflected on the plant root and shoots length, leading only to minimum growth of shoots in P. vulgaris $(5.30 \pm 0.31 \mathrm{~cm}), V$. radiata $(0.80 \pm 0.61 \mathrm{~cm})$ and $P$. lunatus $(0.90 \pm 0.87 \mathrm{~cm})$. 
Similarly, pure RR-194 solution significantly restricted the growth of shoots in P. vulgaris (4.92 $\pm 0.15 \mathrm{~cm}), V$. radiata $(1.12 \pm 0.98 \mathrm{~cm})$ and $P$. lunatus $(1.02 \pm 0.19 \mathrm{~cm})$. On the contrary higher shoot and root lengths were observed in the case of seeds grown in degraded products, as well as, in the control (Table 1) (Fig. 7). Collectively, these phytotoxicity results indicated the ability of

361 the prepared nanoparticles to degrade the toxic contaminants SMX and RR-194 and to reduce the

362 toxicity of the treated water.
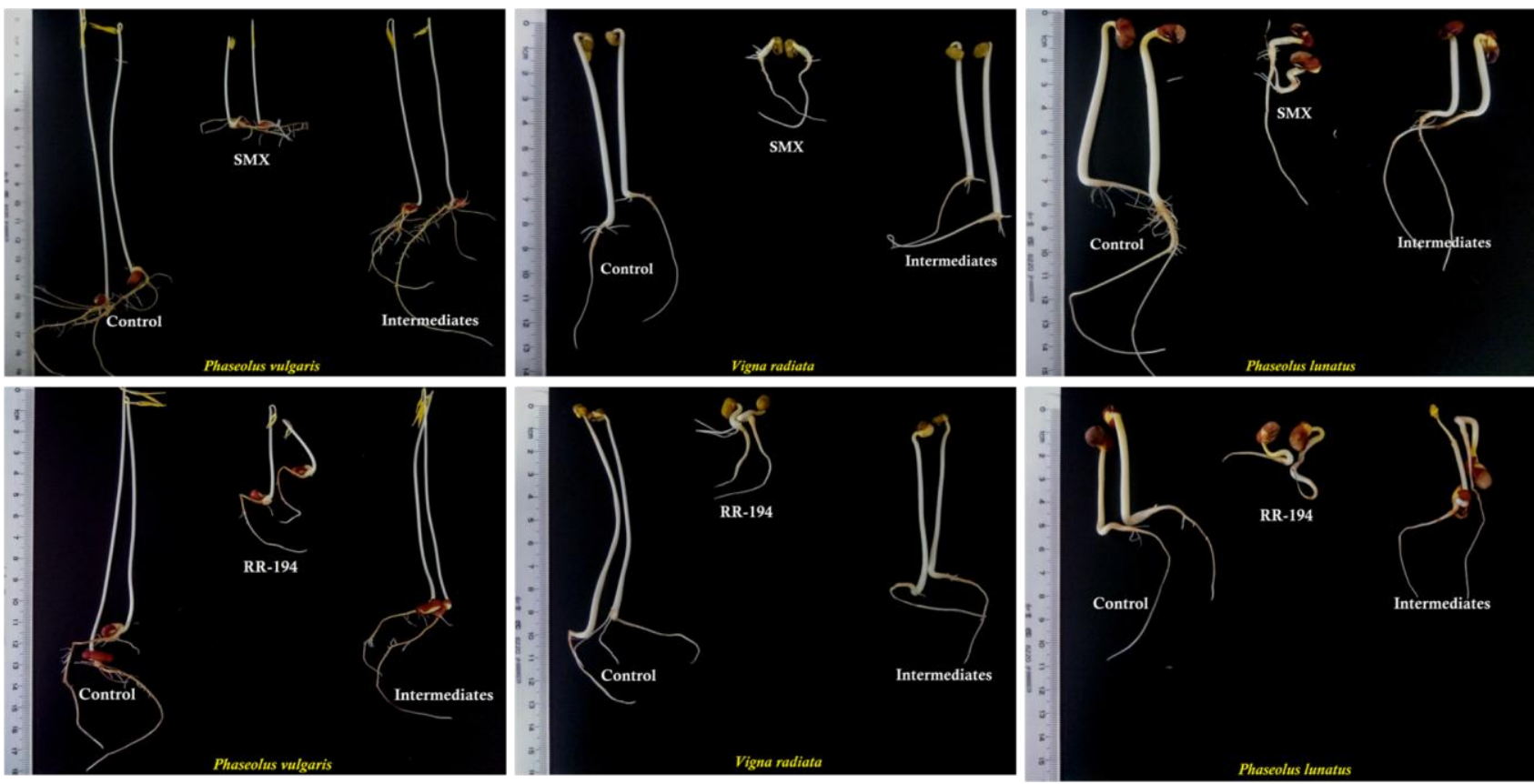

363 Fig. 7 Phytotoxicity assessment of SMX, RR-194 and their metabolites after 5 days

\subsection{Photocatalytic mechanism}

It is well evidenced that ' $\mathrm{Ag}$ ' traps the electrons from $\mathrm{CB}$ of $\mathrm{TiO}_{2}$, while doping with ' $\mathrm{Zr}$ '

reduces the recombination of electrons and holes by further electron trapping [55]. The VB

367 electrons of $\mathrm{Zr} / \mathrm{Ag}-\mathrm{TiO}_{2}$ could easily migrate to the $\mathrm{CB}$ by absorbing visible light, leaving holes

368 in the VB Eq (2). These photogenerated electrons are scavenged by the oxygen molecules

369 absorbed on the surface of the photocatalyst, producing highly reactive superoxide anion radicals

$370\left(\cdot \mathrm{O}_{2}-\right)$, which are according to the scavenging experiments play a key role in the 
371 photodegradation of the contaminants (Eq. 3). Likewise, the photogenerated holes in the VB of $372 \mathrm{TiO}_{2}$ readily oxidize $\mathrm{H}_{2} \mathrm{O}$ and $\mathrm{OH}^{-}$into hydroxyl $(\bullet \mathrm{OH})$ radicals (Eq. 4 and 5$)$, which

373 significantly promote the photodegradation of SMX and RR-194. Thus, hydroxyl $(\bullet \mathrm{OH})$ and 374 superoxide $\left(\cdot \mathrm{O}_{2}-\right)$, radicals are the ROS species on the photocatalyst surface that drive the 375 formation of the degradation products (Eq. 6).
$376 \mathrm{Zr} / \mathrm{Ag}-\mathrm{TiO}_{2}+\mathrm{h} v$
$\longrightarrow \mathrm{Zr} / \mathrm{Ag}^{-\mathrm{TiO}_{2}}\left(\mathrm{eCB}^{-}+\mathrm{hVB}^{+}\right)$
$377 \mathrm{Zr} / \mathrm{Ag}-\mathrm{TiO}_{2}\left(\mathrm{eCB}^{-}\right)+\mathrm{O}_{2} \longrightarrow \quad \mathrm{Zr} / \mathrm{Ag}-\mathrm{TiO}_{2}+\cdot \mathrm{O}_{2}$
$\mathrm{Zr} / \mathrm{Ag}-\mathrm{TiO}_{2}\left(\mathrm{hVB}^{+}\right)+\mathrm{H}_{2} \mathrm{O}$
$\mathrm{Zr} / \mathrm{Ag}-\mathrm{TiO}_{2}+\cdot \mathrm{OH}+\mathrm{H}^{+}$
$379 \mathrm{Zr} / \mathrm{Ag}-\mathrm{TiO}_{2}\left(\mathrm{hVB}^{+}\right)+\mathrm{OH}^{-}$ $\mathrm{Zr} / \mathrm{Ag}-\mathrm{TiO}_{2}+\cdot \mathrm{OH}$
$\mathrm{SMX}$ or $\mathrm{RR}-194+\bullet \mathrm{O}_{2}-+\bullet \mathrm{OH}$
Degradation product

\section{4. Conclusions}

Novel $\mathrm{TiO}_{2}$ nanoparticles modified with silver and zirconium were synthesized and 383 utilized in the photocatalytic degradation of toxic organic pollutants, sulphamethoxazole and reactive red-194 under visible light irradiation. The doping of silver and zirconium improved the photocatalytic activity of $\mathrm{TiO}_{2}$ under visible light illumination, which resulted from the decrease 386 of the band gap energy. The plausible transformation pathway and degradation products were 387 determined by LC/ESI-MS analysis and the reaction mechanisms were elucidated with radical 388 scavenging experiments. According to phytotoxicity assessment it is suggested that the degraded 389 products induces better growth in root and shoots compare to pure SMX and RR-194 in all three 390 crop seeds ( $P$. vulgaris, $V$. radiata and $P$. lunatus), which evidenced that less toxic intermediates 391 were generated during degradation process. Thus, we conceive that the present study provides 392 manifest of $\mathrm{Zr} / \mathrm{Ag}-\mathrm{TiO}_{2}$ multifunctional nanomaterials to simultaneously degrade and detoxify 
393 the contaminated water during photocatalysis under visible light irradiation and to provide a 394 potential and effective method for water reuse and for crop irrigation.

395 Acknowledgements

396 The study was financially supported by the National Natural Science Foundation of 397 China for Foreign Youth Scholars (Grant No. 51650110501), the China Postdoctoral Science 398 Foundation (Grant No. 2016M591767), the Foundation for Innovative Research Groups of the 399 National Natural Science Foundation of China (Grant No. 51421006), Program for 400 Environmental Protection in Jiangsu Province (Grant No. 2015037), and Priority Academic 401 Program Development of Jiangsu Higher Education Institutions. The Fundamental Research 402 Funds for the Central Universities (Grant No. 2016B10614), Priority Academic Program 403 Development of Jiangsu Higher Education Institutions, and Top-notch Academic Programs 404 project of Jiangsu Higher Education Institutions (TAPP)

405 References

406 [1] B. Chen, Y. Yang, X. Liang, K. Yu, T. Zhang, X. Li, Metagenomic profiles of 407 408 409 antibiotics resistance genes (ARGs) between human impacted estuary and deep ocean sediments, Environ. Sci. Technol. 47 (2013a) 12753-12760.

[2] Y. Luo, D. Mao, M. Rysz, Q. Zhou, H. Zhang, L. Xu, P.J.J. Alvarez, Trends in antibiotics resistance genes occurrence in the Haihe River, China, Environ. Sci. Technol. 44 (2010) 7220-7225.

414 415

[3] Q.Q. Zhang, G.G. Ying, C.G. Pan, Y.S. Liu, J.L. Zhao, Comprehensive evaluation of antibiotics emission and fate in the river basins of China: source analysis, multimedia modeling, and linkage to bacterial resistance, Environ. Sci. Technol. 49 (2015) 67726782. 
[4] L. Rizzo, C. Manaia, C. Merlin, T. Schwartz, C. Dagot, M.C. Ploy, I. Michael, D. Fatta-Kassinos, Urban wastewater treatment plants as hotspots for antibiotic resistant bacteria and genes spread into the environment: a review, Sci. Total Environ. 447 (2013) $345-360$.

420

[5] A. Shimizu, H. Takada, T. Koike, A. Takeshita, M. Saha, Rinawati, N. Nakada, A. Murata, T. Suzuki, S. Suzuki, N.H. Chiem, B.C. Tuyen, P.H. Viet, M.A. Siringan, C. Kwan, M.P. Zakaria, A. Reungsang, Ubiquitous occurrence of sulfonamides in tropical Asian waters, Sci. Total Environ. 452-453 (2013) 108-115.

[6] R. Mohammadi, B. Massoumi, M. Rabani, Photocatalytic Decomposition of 425 [7] T. Deblonde, C. Cossu-Leguille, P. Hartemann, Emerging pollutants in wastewater: A review of the literature, Int. J. Hyg. Environ. Health. 214 (2011) 442-448. Environ. Sci. Technol. 38 (2004) 3933-3940.

[9] K. Kümmerer, Antibiotics in the aquatic environment-A review-Part I, Chemosphere. 75 (2009) 417-434.

[10] A. Dirany, I. Sirés, N. Oturan, M.A. Oturan, Electrochemical abatement of the antibiotic sulfamethoxazole from water, Chemosphere 81 (2010) 594-602.

[11] S. Pérez, P. Eichhorn, D.S. Aga, Evaluating the biodegradability of sulfamethazine, sulfamethoxazole, sulfathiazole, and trimethoprim at different stages of sewage treatment, Environ. Toxicol. Chem. 24 (2005) 1361-1367. 
[12] M. Cleuvers, Aquatic ecotoxicity of pharmaceuticals including the assessment of combination effects, Toxicol. Lett. 142 (2003) 185-194.

[13] M. Cleuvers, Mixture toxicity of the anti-inflammatory drugs diclofenac, ibuprofen, naproxen, and acetylsalicylic acid, Ecotoxicol. Environ. Saf. 59 (2004) 309-315.

443

[14] A. Wang, Y.Y. Li, A.L. Estrada, Mineralization of antibiotic sulfamethoxazole by photoelectro-Fenton treatment using activated carbon fiber cathode and under UVA irradiation, Appl. Catal. B 102 (2011) 378-386.

[15] R. Wei, F. Ge, S. Huang, M. Chen, R. Wang, Occurrence of veterinary antibiotics in animal wastewater and surface water around farms in Jiangsu Province, China, Chemosphere 82 (2011) 1408-1414.

[16] M. Gonzalez, T. Hashem, L. Jakob, A. Braum, Oxidative degradation of nitrogencontaining organic compounds: vaccum-ultraviolet (VUV) photolysis of aqueous solutions of 3-amino 5-methylisoxazole, Fresenius' J. Anal. Chem. 351 (1995) 92-97.

[17] M.d.M. Gomez-Ramos, M. Mezcua, A. Agüera, A.R. Fern_andez-Alba, S. Gonzalo, A. Rodríguez, R. Rosal, Chemical and toxicological evolution of the antibiotic sulfamethoxazole under ozone treatment in water solution, J. Hazard. Mater. 192 (2011), $18-25$.

[18] S. Gao, Z. Zhao, Y. Xu, J. Tian, H. Qi, W. Lin, F. Cui, Oxidation of sulfamethoxazole (SMX) by chlorine, ozone and permanganateda comparative study, J. Hazard. Mater. 274 (2014) 258-269.

[19] A.G. Trovo, R.F. Nogueira, A. Agüera, A.R. Fernandez-Alba, C. Sirtori, S. Malato, Degradation of sulfamethoxazole in water by solar photo-Fenton: Chemical and toxicological evaluation, Water. Res. 43 (2009) 3922-3931. 
[20] B. Jiang, A. Li, D. Cui, R. Cai, F. Ma, Y. Wang, Biodegradation and metabolic pathway of sulfamethoxazole by Pseudomonas psychrophila HA-4, a newly isolated cold-adapted sulfamethoxazole-degrading bacterium, Appl. Microbiol. Biotechnol. 98 (2014) 4671-4681.

[21] B. Ricken, P.F. Corvini, D. Cichocka, M. Parisi, M. Lenz, D. Wyss, P.M. MartínezLavanchy, J.A. Müller, P. Shahgaldian, L.G. Tulli, Ipso-hydroxylation and subsequent fragmentation: a novel microbial strategy to eliminate sulfonamide antibiotics, Appl. Environ. Microbiol. 79 (2013) 5550-5558.

[22] G. R. Li, D. L. Qu, W. X. Zhao, Y. X. Tong, Electrochemical deposition of (Mn, Co)-codoped $\mathrm{ZnO}$ nanorod arrays without any template, Electrochem. Commun. 9 (2007) $1661-1666$.

[23] Z. Wang, C. Chen, F. Wu, B. Zou, M. Zhao, J. Wang, C. Feng, Photodegradation of rhodamine $\mathrm{B}$ under visible light by bimetal codoped $\mathrm{TiO}_{2}$ nanocrystals, J. Hazard. Mater. 164 (2009) 615-620.

[24] L. Gnanasekaran, R. Hemamalini, R. Saravanan, K. Ravichandran, F. Gracia, Vinod Kumar Gupt, Intermediate state created by dopant ions $\left(\mathrm{Mn}\right.$, $\mathrm{Co}$ and $\mathrm{Zr}$ ) into $\mathrm{TiO}_{2}$ nanoparticles for degradation of dyes under visible light, J. Mol. Liq. 223 (2016) 652659.

[25] Zheng-Hui Ren, Hai-Tao Li, Qiang Gao, HaoWang, Bo Han, Kai-Sheng Xia, Cheng-Gang Zhou, $\mathrm{Au}$ nanoparticles embedded on urchin-like $\mathrm{TiO}_{2}$ nanosphere: An efficient catalyst for dyes degradation and 4-nitrophenol reduction, Mater. Des. 121 (2017) 167-175. 
[26] Yujie He, Nora B. Sutton, Huub H.H. Rijnaarts, Alette A.M. Langenhoff,

485

486

487

488

489

490

491

492

493

494

495

496

497

498

499

500

501

502

503

504

Degradation of pharmaceuticals in wastewater using immobilized $\mathrm{TiO}_{2}$ photocatalysis under simulated solar irradiation, Appl. Catal. B 182 (2016) 132-141.

[27] Lu Lin, Huiyao Wang, Pei $\mathrm{Xu}$, Immobilized $\mathrm{TiO}_{2}$-reduced graphene oxide nanocomposites on optical fibers as high performance photocatalysts for degradation of pharmaceuticals, Chem. Eng. J. 310 (2017) 389-398.

[28] R. Aiswal, N. Patel, A. Dashora, R. Fernandes, M. Yadav, R. Edla, R.S. Varma, D.C. Kothari, BL Ahuja, A. Miotello, Efficient Co-B-codoped $\mathrm{TiO}_{2}$ photocatalyst for degradation of organic water pollutant under visible light, Appl. Catal. B 183 (2016) 242253.

[29] Q. Guo, Z. Zhang, X. Ma, K. Jing, M. Shen, N. Yu, J. Tang, D.D. Dionysiou, Preparation of N,F-codoped $\mathrm{TiO}_{2}$ nanoparticles by three different methods and comparison of visible-light photocatalytic performances Separ. Puri. Techn. 175 (2017) 305-313.

[30] D. Das, H.K. Mishra, K.M. Parida, A.K. Dalai, Preparation, physico-chemical characterization and catalytic activity of sulphated $\mathrm{ZrO}_{2}-\mathrm{TiO}_{2}$ mixed oxides, J. Mol. Catal. A Chem. 189 (2002) 271-282.

[31] Saraschandra Naraginti, Finian Bernard Stephen, Adhithya Radhakrishnan, A. Sivakumar, Zirconium and silver co-doped $\mathrm{TiO}_{2}$ nanoparticles as visible light catalyst for reduction of 4-nitrophenol, degradation of methyl orange and methylene blue, Spectrochim. Acta, Part A. 135 (2015) 814-819. 
[32] A. Hernández-Gordillo, V. Rodríguez González, Silver nanoparticles loaded on Cudoped $\mathrm{TiO} 2$ for the effective reduction of nitro-aromatic contaminants, Chem. Eng. J. 261 (2015) 53-59.

508

509

[33] E. Bilgin Simsek, Solvothermal synthesized boron doped $\mathrm{TiO}_{2}$ catalysts: Photocatalytic degradation of endocrine disrupting compounds and pharmaceuticals under visible light irradiation, Appl. Catal. B. 200 (2017) 309-322.

[34] L. Wang, Y. Liu, J. M, F. Zhao, Rapid degradation of sulphamethoxazole and the further transformation of 3-amino-5-methylisoxazole in a microbial fuel cell, Water. Res. 88 (2016) $322-328$

[35] S. Song, L. Xu, Z. He, H. Ying, J. Chen, X. Xi and B. Yan, Photocatalytic degradation of C.I. Direct Red 23 in aqueous solutions under UV irradiation using $\mathrm{SrTiO}_{3} / \mathrm{CeO}_{2}$ composite as the catalyst, J. Hazard. Mater. 152 (2008) 1301-1308.

[36] Y. Fu, H. Chen, X. Sun and X. Wang, Combination of cobalt ferrite and graphene: High-performance and recyclable visible-light photocatalysis, Appl. Catal. B. 111-112 (2012) 280-287.

[37] L. S. Zhang, K. H. Wong, H. Y. Yip, C. Hu, J. C. Yu, C. Y. Chan and P. K. Wong, Effective photocatalytic disinfection of $E$. coli $\mathrm{K}-12$ using $\mathrm{AgBr}-\mathrm{Ag}-\mathrm{Bi}_{2} \mathrm{WO}_{6}$ nanojunction system irradiated by visible light: The role of diffusing hydroxyl radicals, Environ. Sci. Technol. 44 (2010) 1392-1398.

[38] Z. Pan, E. Stemmler, H. J. Cho, W. Fan, L. LeBlanc, H. H. Patterson and A. Amirbahman, Photocatalytic degradation of $17 \alpha$-ethinylestradiol (EE2) in the presence of $\mathrm{TiO}_{2}$-doped zeolite, J. Hazard. Mater. 279 (2014) 17-25. 
[39] USEPA, Ecological effects test guidelines. Seed germination root elongationtoxicity test. Office of prevention, Pesticides and Toxic substances 850 4200. Washington DC. EPA 712-C-96-163 (1996).

[40] A.S. Arun Prasad, V.S.V. Satyanarayana, K.V. Bhaskar Rao, Biotransformation of Direct Blue 1 by a moderately halophilic bacterium Marinobacter sp. strain HBRA and toxicity assessment of degraded metabolites, J. Hazard. Mater. 262 (2013) 674- 684.

[41] M. Saquiba, M.A. Tariq, M. Faisal, M. Muneer, Photocatalytic degradation of two selected dye derivatives in aqueous suspensions of titanium dioxide, Desalination 219 (2008) 301-311.

[42] M.A. Habiba, I.M.I. Ismail, A.J. Mahmood, M.R. Ullah, Photocatalytic decolorization of brilliant golden yellow in $\mathrm{TiO}_{2}$ and $\mathrm{ZnO}$ suspensions, J. Saudi. Chem. Soc. 16 (2012) 423-429.

[43] Amit Kumar Behera, Ch Venkatanarasimha Rao, Raj Kumar Das, Ardhendu Sekhar Giri \& Animes Kumar Golder, Fabrication and characterization of Ag-doped titania: impact of dye-sensitization, phenol decomposition kinetics and biodegradability index, Desalination and Water Treatment. 57 (2016) 9488-9497.

[44] E. Sumesh, M.S. Bootharaju, Anshup, T. Pradeep, A practical silver nanoparticlebased adsorbent for the removal of $\mathrm{Hg}^{2+}$ from water, J. Hazard. Mater. 189 (2011) 450457.

[45] Y. Lai, H. Zhang, K. Xie, D. Gong, Y. Tang, L. Sun, C. Lin, Z. Chen, Fabrication of uniform $\mathrm{Ag} / \mathrm{TiO}_{2}$ nanotube array structures with enhanced photoelectrochemical performance, New J. Chem. 34 (2010) 1335-1340. 
[46] T. sunekawa, K. Asami, S. Ito, M. Yashima and T. Sugimoto, XPS study of the phase transition in pure zirconium oxide nanocrystallites, Appl. Surf. Sci. 252 (2005) $1651-1656$

[47] K. V. Bineesh, S. Y. Kim, B. R. Jermy and D. W. Park, Catalytic performance of vanadia-doped titania-pillared clay for the selective catalytic oxidation of $\mathrm{H}_{2} \mathrm{~S}$, J. Ind. Eng. Chem. 15 (2009) 207-211.

[48] Y. Kim, J. Lee, H. Jeong, Y. Lee, M. H. Um, K. M. Jeong, M. K. Yeo and M. Kang, Methyl orange removal over $\mathrm{Zn}$-incorporated $\mathrm{TiO}_{2}$ photo-catalyst, J. Ind. Eng. Chem. 14 (2008) 396-400.

[49] K. I. Ishibashi, A. Fujishima, T. Watanab and K. Hashimoto, Detection of active oxidative species in $\mathrm{TiO} 2$ photocatalysis using the fluorescence technique, Electrochem. Commun. 2 (2000) 207-210.

[50] N. Arunkumar, R. Vijayaraghavan, Enhanced Photocatalytic activity of Nanocrystalline $\mathrm{N}$ - doped $\mathrm{ZnSb}_{2} \mathrm{O}_{6}$ : role of $\mathrm{N}$ doping, cation ordering, particle size and crystallinity, RSC Adv. 4 (2014) 65223-65231.

[51] S. Naraginti, Y. Li and Y. Wu, A visible light mediated synergistic catalyst for effective inactivation of E. coli and degradation of azo dye Direct Red-22 with mechanism investigation, RSC Adv. 6 (2016) 75724-75735.

[52] N. Tian, H. Huang, Y. He, Y. Guo, T. Zhang, Y. Zhang, Mediator-free direct Zscheme photocatalytic system: $\mathrm{BiVO}_{4} / \mathrm{g}-\mathrm{C}_{3} \mathrm{~N}_{4}$ organic-inorganic hybrid photocatalyst with highly efficient visible-light-induced photocatalytic activity, Dalton Trans. 7 (2015) 4297-4307. 
[53] L. F. Chiang, R. Doong, Enhanced photocatalytic degradation of sulfamethoxazole by visible-light-sensitive $\mathrm{TiO}_{2}$ with low $\mathrm{Cu}$ addition, Sep. Purif. Technol. 156 (2015) $1003-1010$.

[54] A. G. Gonc, alves, J.J.M. Órfão, M.F. R. Pereira, Catalytic ozonation of sulphamethoxazole in the presence of carbon materials: Catalytic performance and reaction pathways, J. Hazard. Mater. 239- 240 (2012) 167- 174.

[55] S.T. Pantelides, The electronic structure of impurities and other point defects in semiconductors, Rev. Mod. Phys. 50 (1978) 797-858. 
Table 1. Phytotoxicity assessment of SMX, RR-194 and their corresponding degraded metabolites (after 5 days)

\begin{tabular}{lccccc}
\hline & Water & SMX & $\begin{array}{c}\text { SMX } \\
\text { metabolites }\end{array}$ & RR-194 & $\begin{array}{c}\text { RR-194 } \\
\text { metabolites }\end{array}$ \\
\hline $\begin{array}{l}\text { Phaseolus vulgaris } \\
\text { Germination (\%) }\end{array}$ & 100 & 40 & 100 & 40 & 100 \\
Shoot (cm) & $13.27 \pm 0.57^{*}$ & $5.30 \pm 0.31^{* *}$ & $10.15 \pm 0.51^{*}$ & $4.92 \pm 0.15^{* *}$ & $9.45 \pm 1.21$ \\
Root (cm) & $7.67 \pm 0.63^{*}$ & $1.43 \pm 0.15^{* *}$ & $5.92 \pm 0.24^{* *}$ & $2.41 \pm 0.34^{* *}$ & $5.87 \pm 1.01$ \\
Vigna radiata & & & & & \\
Germination (\%) & 100 & 30 & 100 & 50 & 100 \\
Shoot (cm) & $8.47 \pm 0.17^{* *}$ & $0.80 \pm 0.61^{*}$ & $6.65 \pm 0.59$ & $1.12 \pm 0.98$ & $7.54 \pm 1.66$ \\
Root (cm) & $5.96 \pm 0.51^{*}$ & $2.54 \pm 0.31^{* *}$ & $4.22 \pm 0.54$ & $3.11 \pm 1.04$ & $4.71 \pm 0.61 *$ \\
Phaseolus lunatus & & & & & \\
Germination (\%) & 100 & 30 & 100 & 30 & 100 \\
Shoot (cm) & $7.98 \pm 0.57^{*}$ & $0.90 \pm 0.87$ & $4.78 \pm 1.01$ & $1.02 \pm 0.19 * *$ & $4.75 \pm 0.67 *$ \\
Root (cm) & $8.17 \pm 0.38^{* *}$ & $2.19 \pm 1.05$ & $6.62 \pm 0.94$ & $1.81 \pm 0.74$ & $5.12 \pm 0.86$ \\
\hline Valus & & & & & \\
\hline
\end{tabular}

Values are mean of germination seeds treated with SMX, RR-194 and degraded metabolites, significantly different from the seeds germinated with tap water at ${ }^{*} \mathrm{P}<0.05,{ }^{* *} \mathrm{P}<0.01$, by one-way analysis of variance (ANOVA). 
Fig. 1
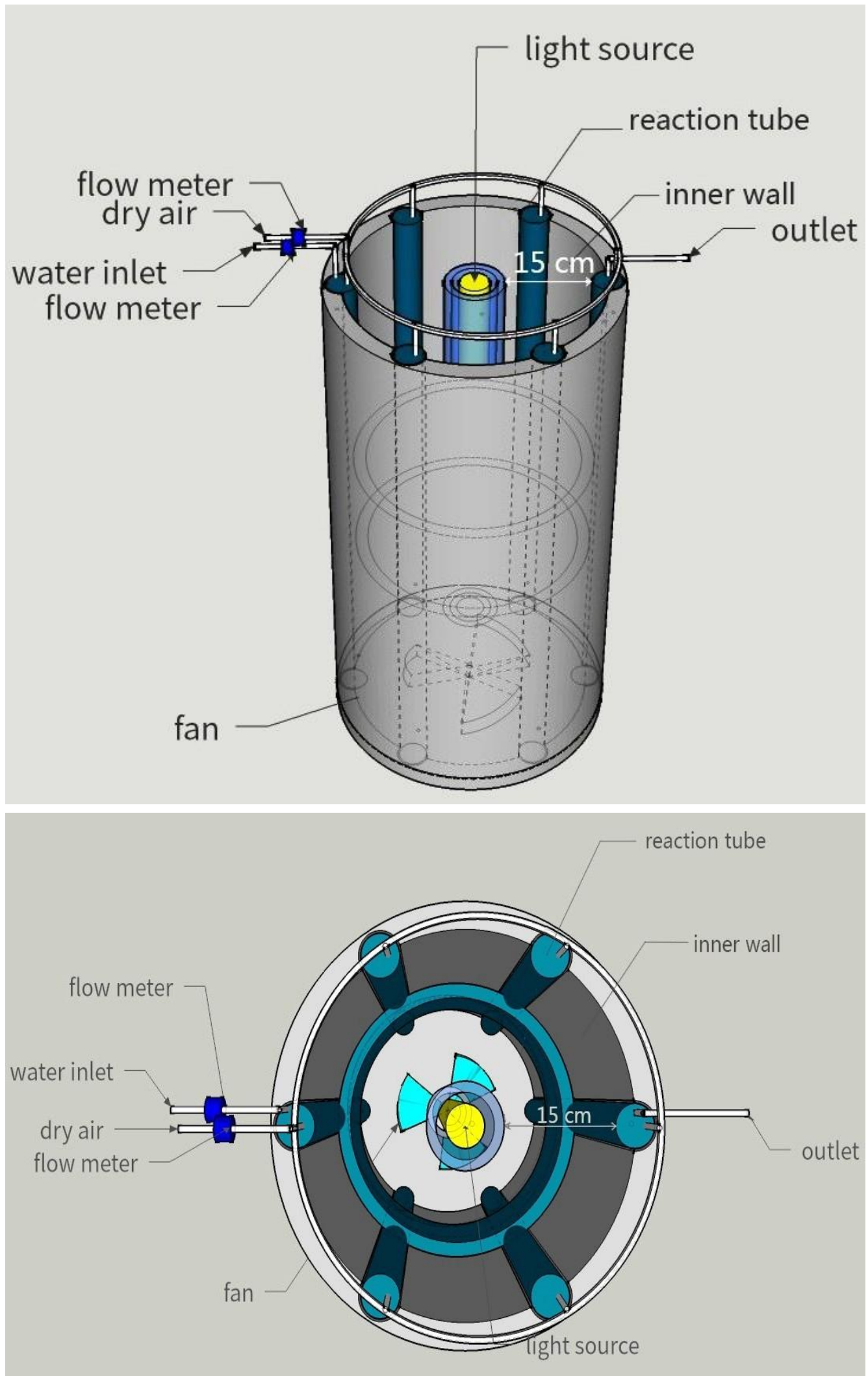
Fig. 2
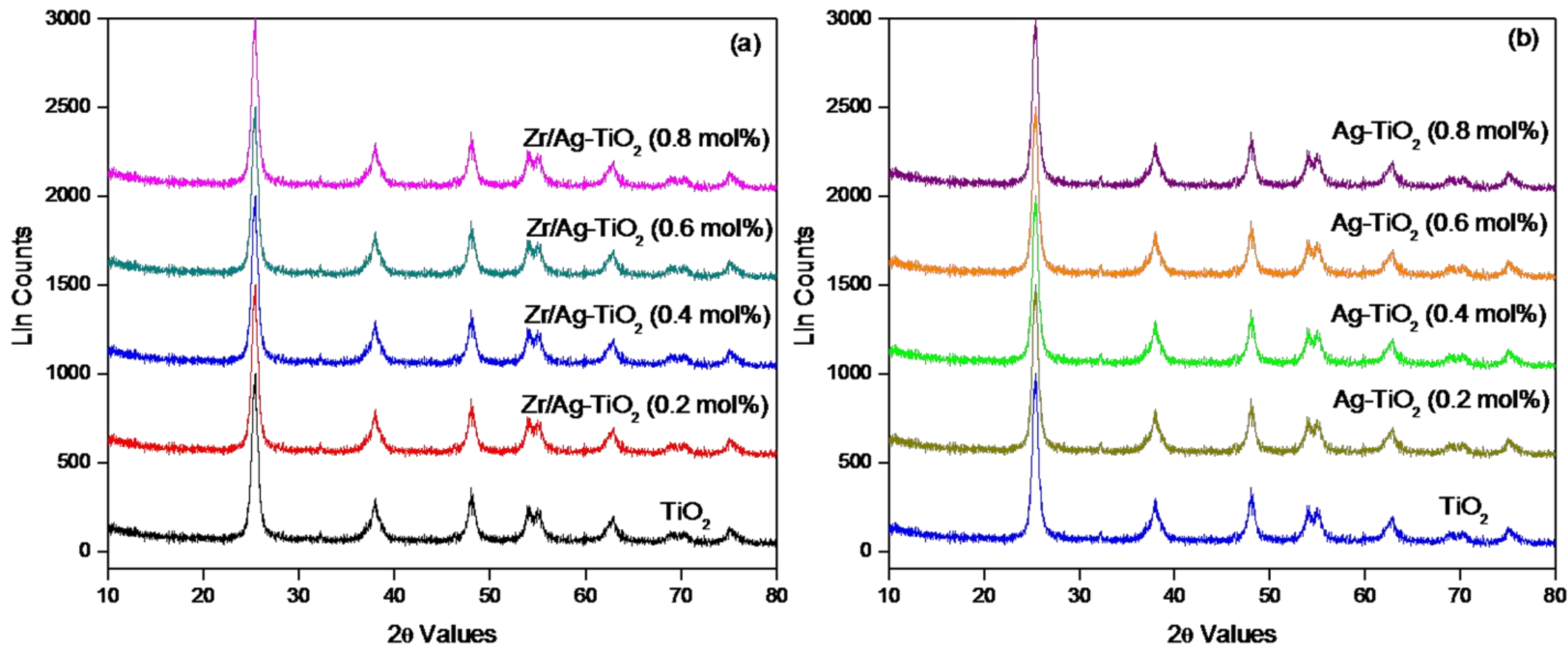
Fig. 3
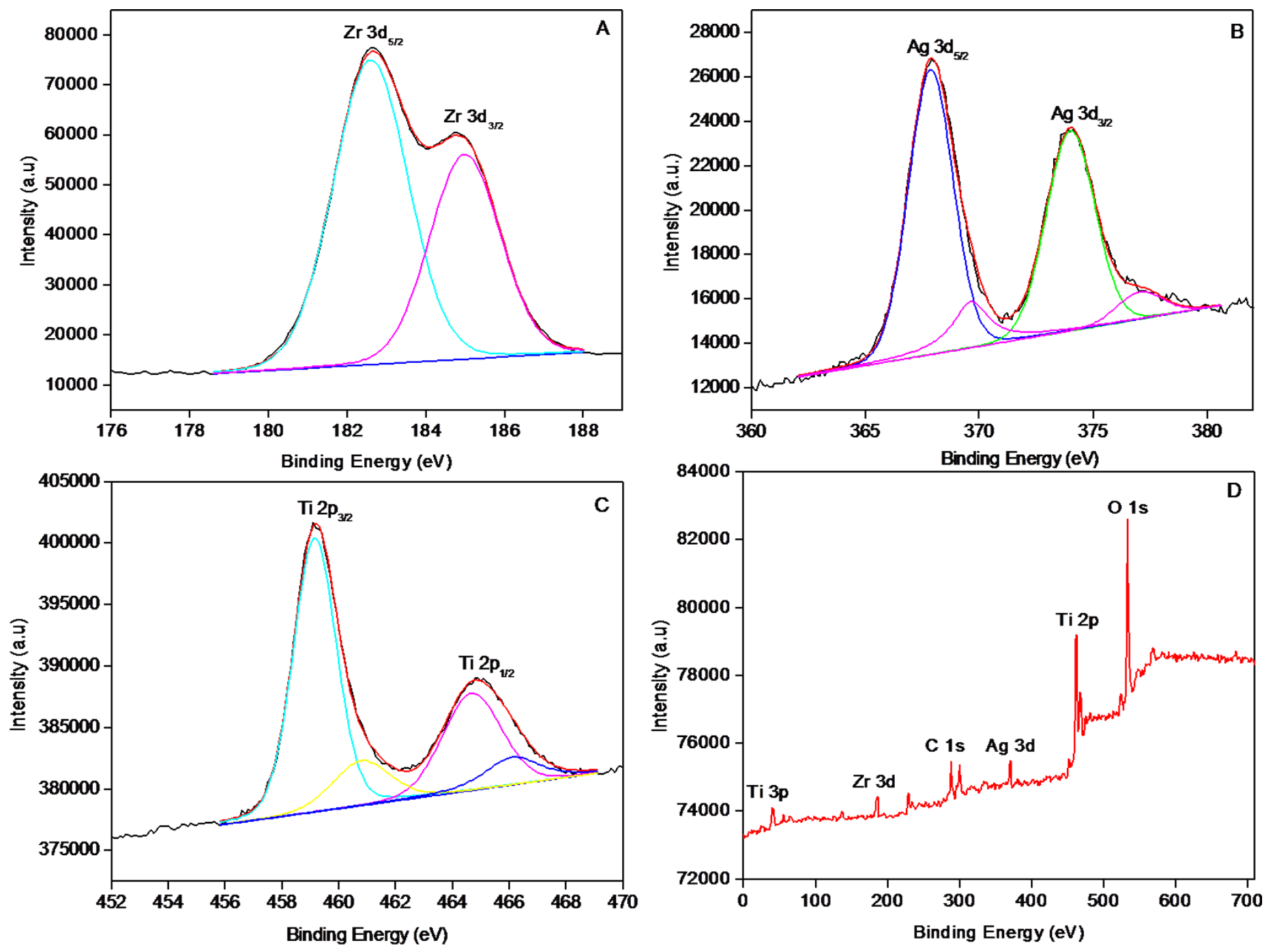
Fig. 4
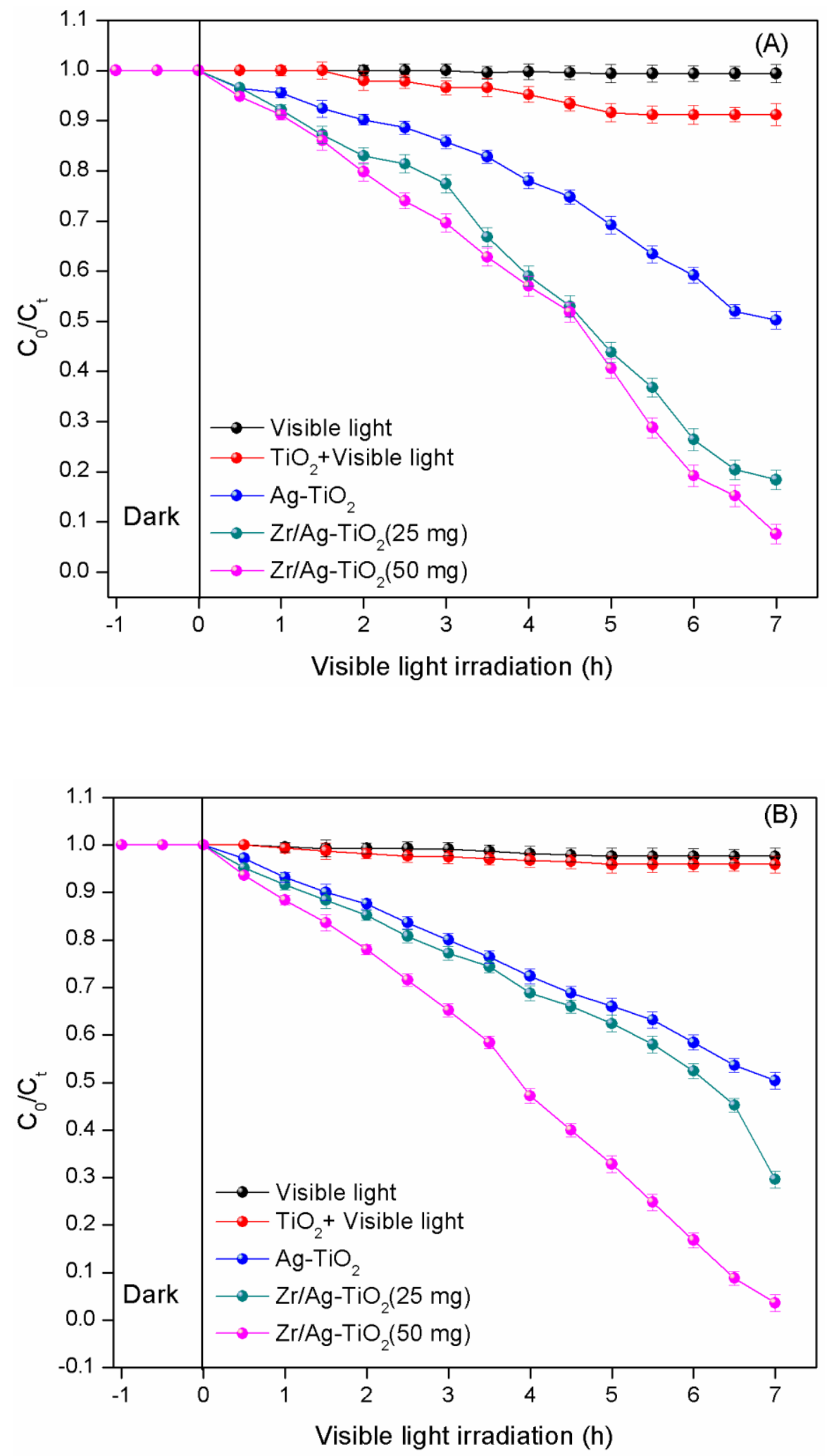
Fig. 5

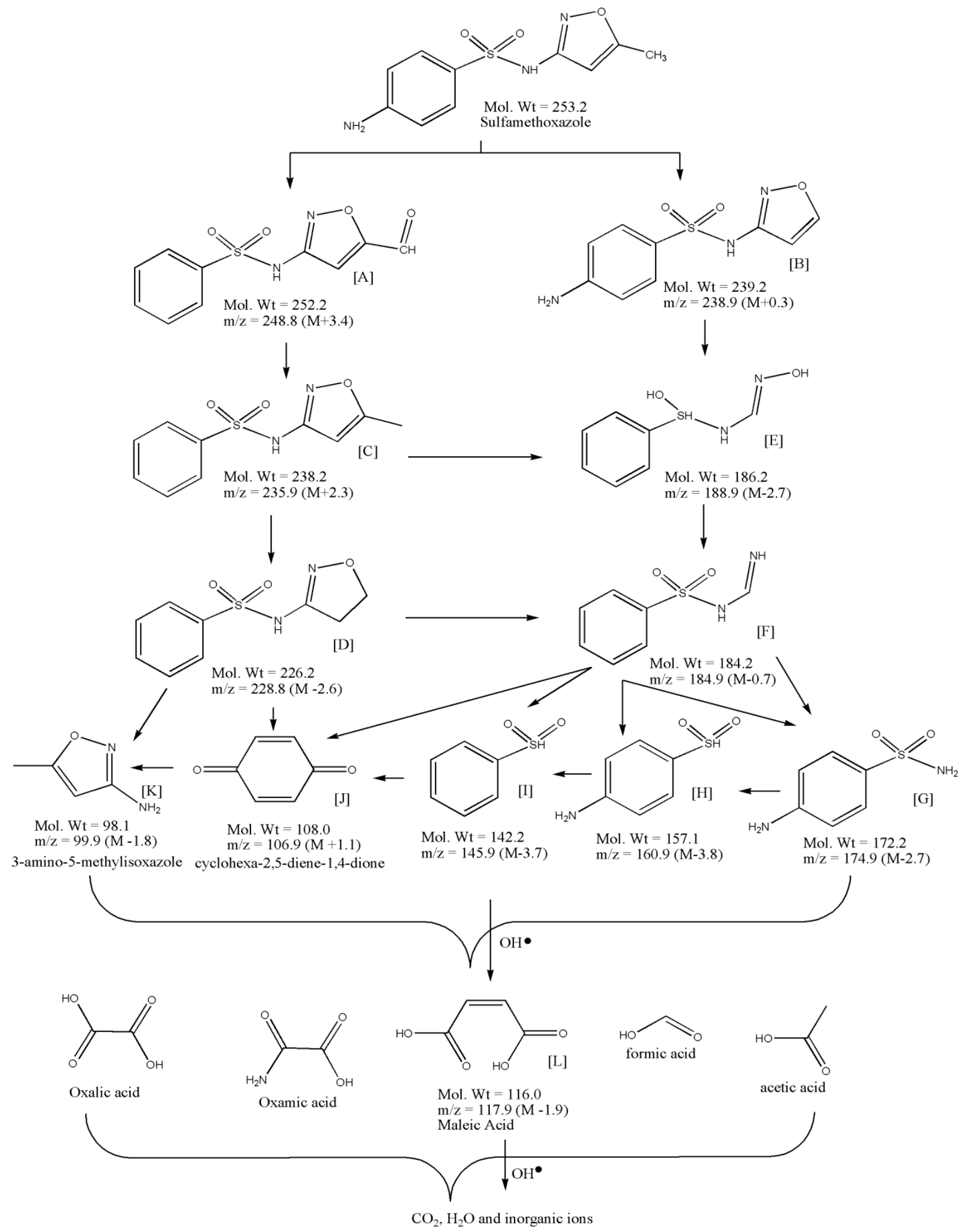


Fig.6

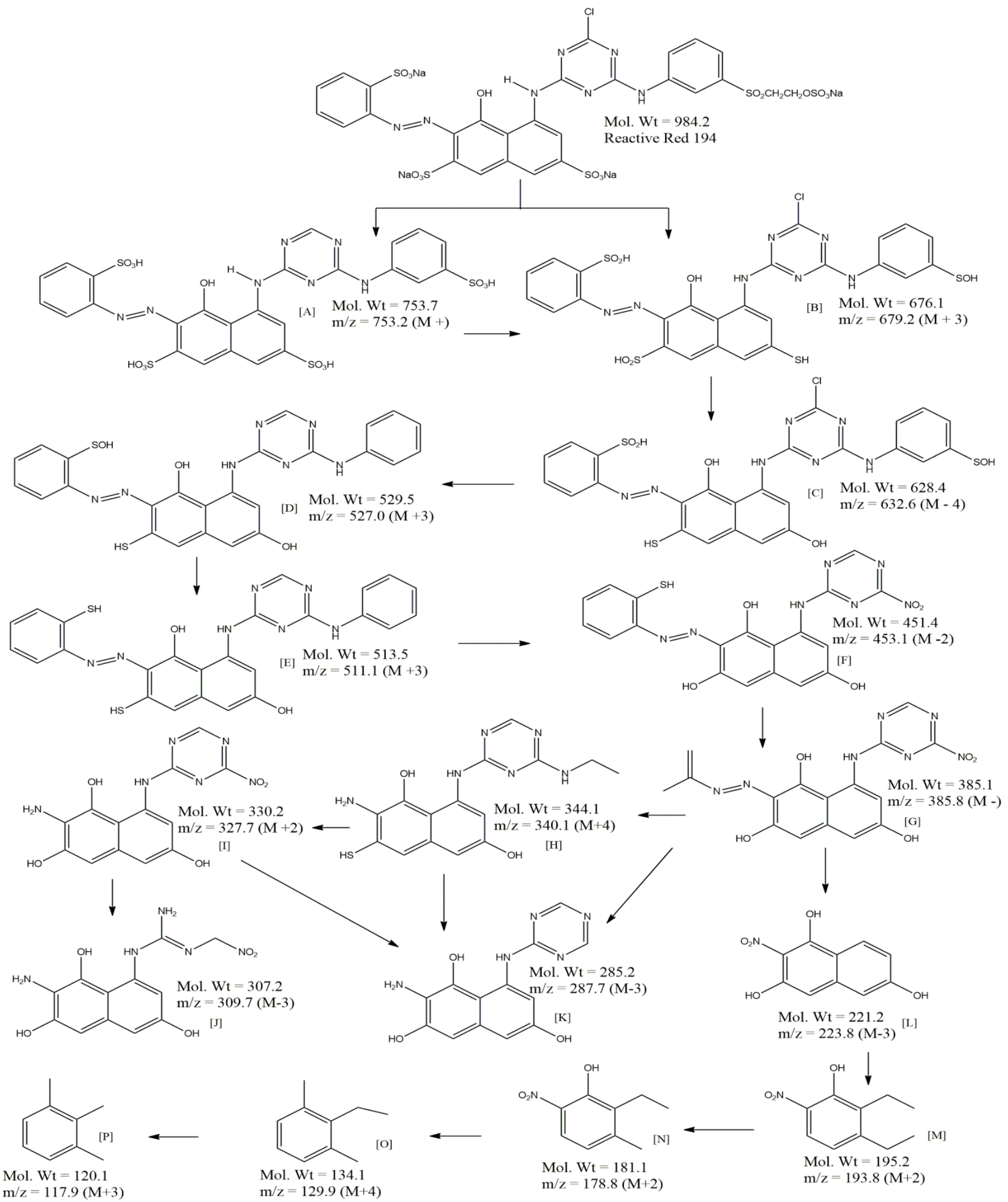


Fig.7
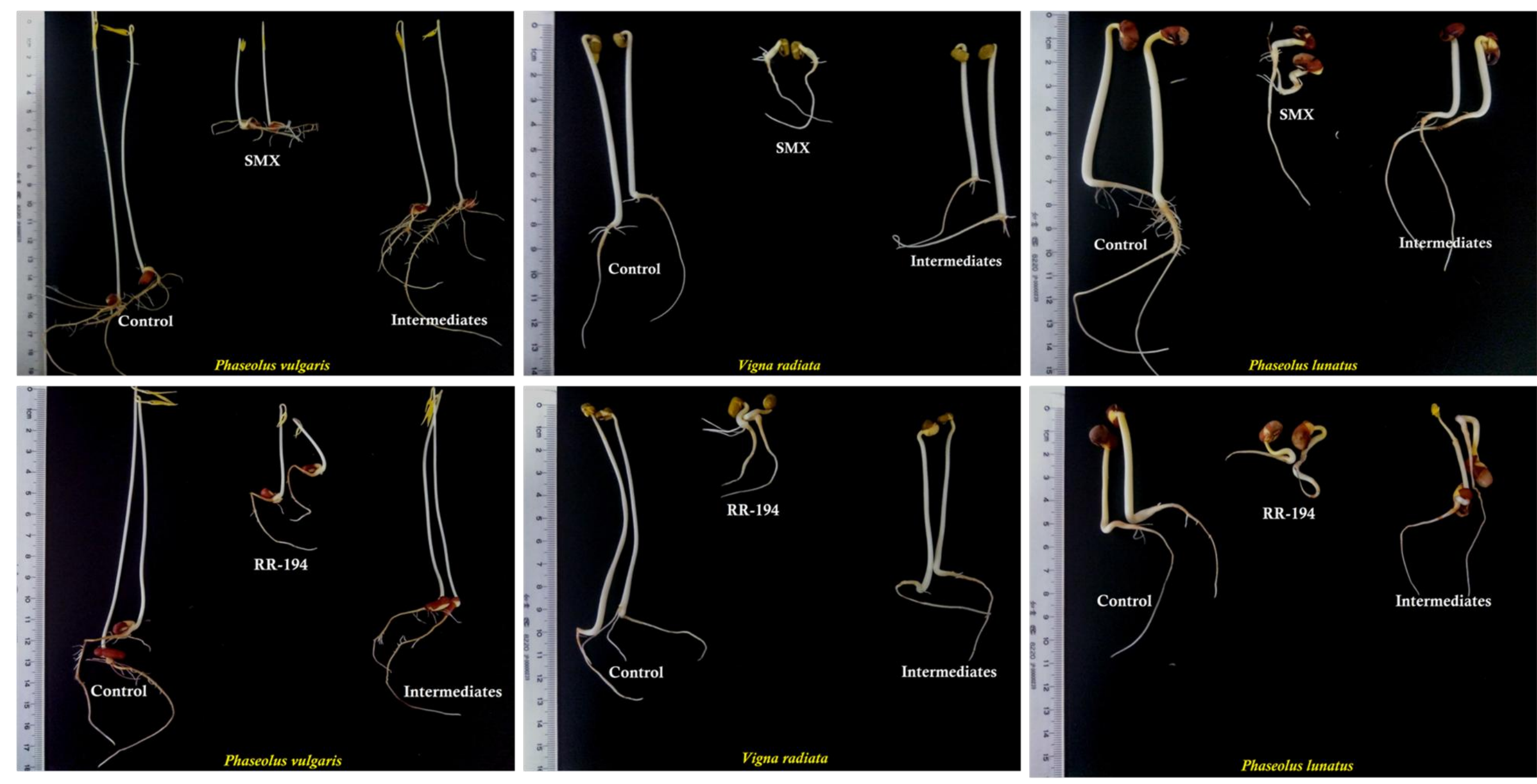


\section{Photocatalytic mineralization and degradation kinetics of sulphamethoxazole and reactive red 194 over silver-zirconium co-doped titanium dioxide: Reaction mechanisms, degradation products and phytotoxicity}

\section{Saraschandra Naraginti ${ }^{\mathrm{a}}, \mathrm{Yi} \underline{\mathrm{Li}}^{\mathrm{a} *}$, Gianluca $\underline{\mathrm{Li} \text { Puma }}^{\mathrm{b} *}$}

${ }^{a}$ Key Laboratory of Integrated Regulation and Resource Development on Shallow Lakes, Ministry of Education, College of Environment, Hohai University, Nanjing - 210098, PR China

${ }^{\mathrm{b}}$ Environmental Nanocatalysis \& Photoreaction Engineering, Department of Chemical Engineering, Loughborough University, Loughborough LE11 3TU, United Kingdom

Fig. S1 (a) UV-Vis spectra, (b) optical energy gap (Eg) and PL spectra (c) of the prepared nanoparticles
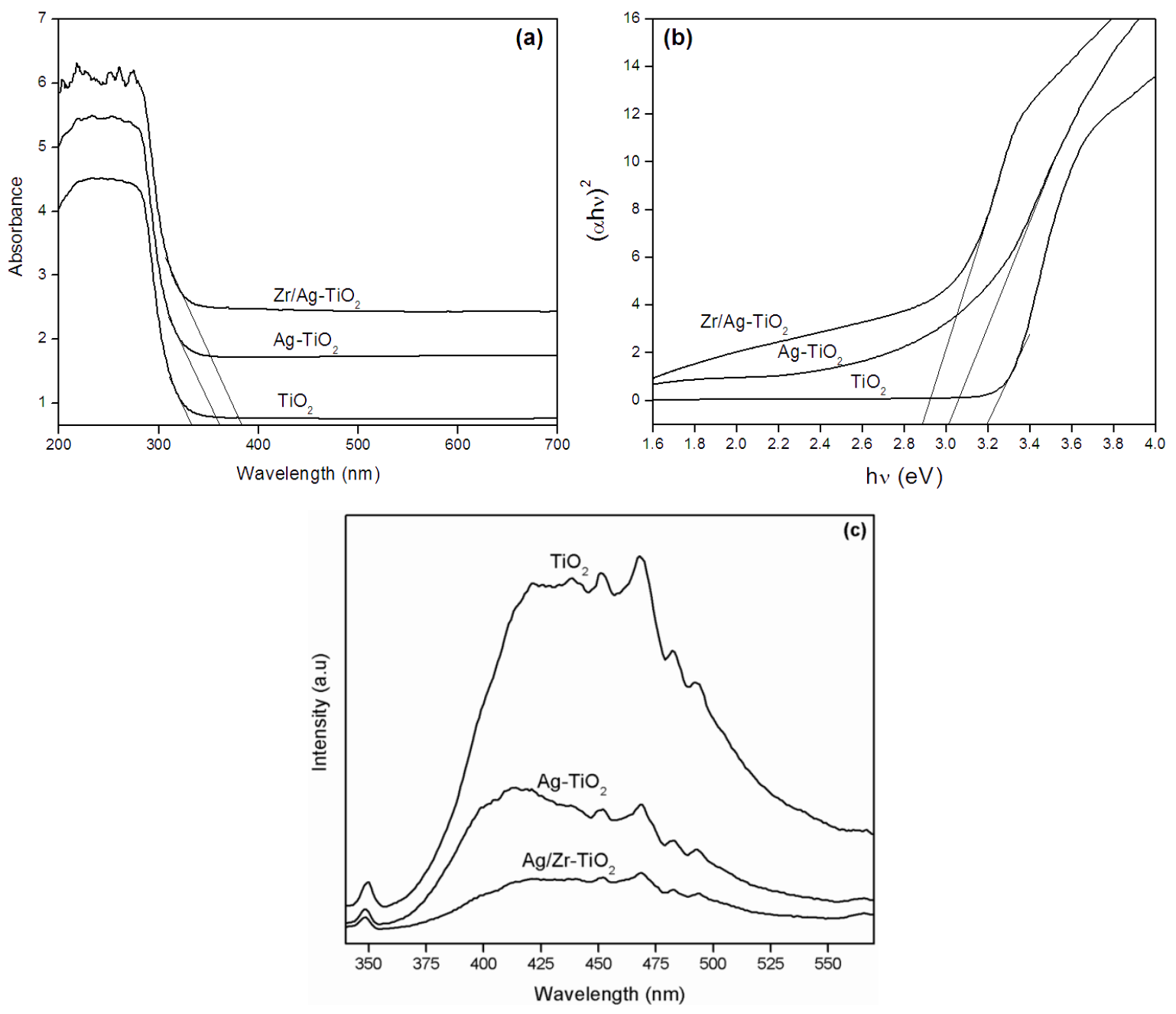

) 
Fig. S2 TEM image of $\mathrm{Ag}-\mathrm{TiO}_{2}$ nanoparticles (a), HR-TEM image shows microstructure information (b), selected area electron diffraction pattern of the doped nanoparticles (c) and EDAX profile (d) showing the elements present in the doped nanoparticles
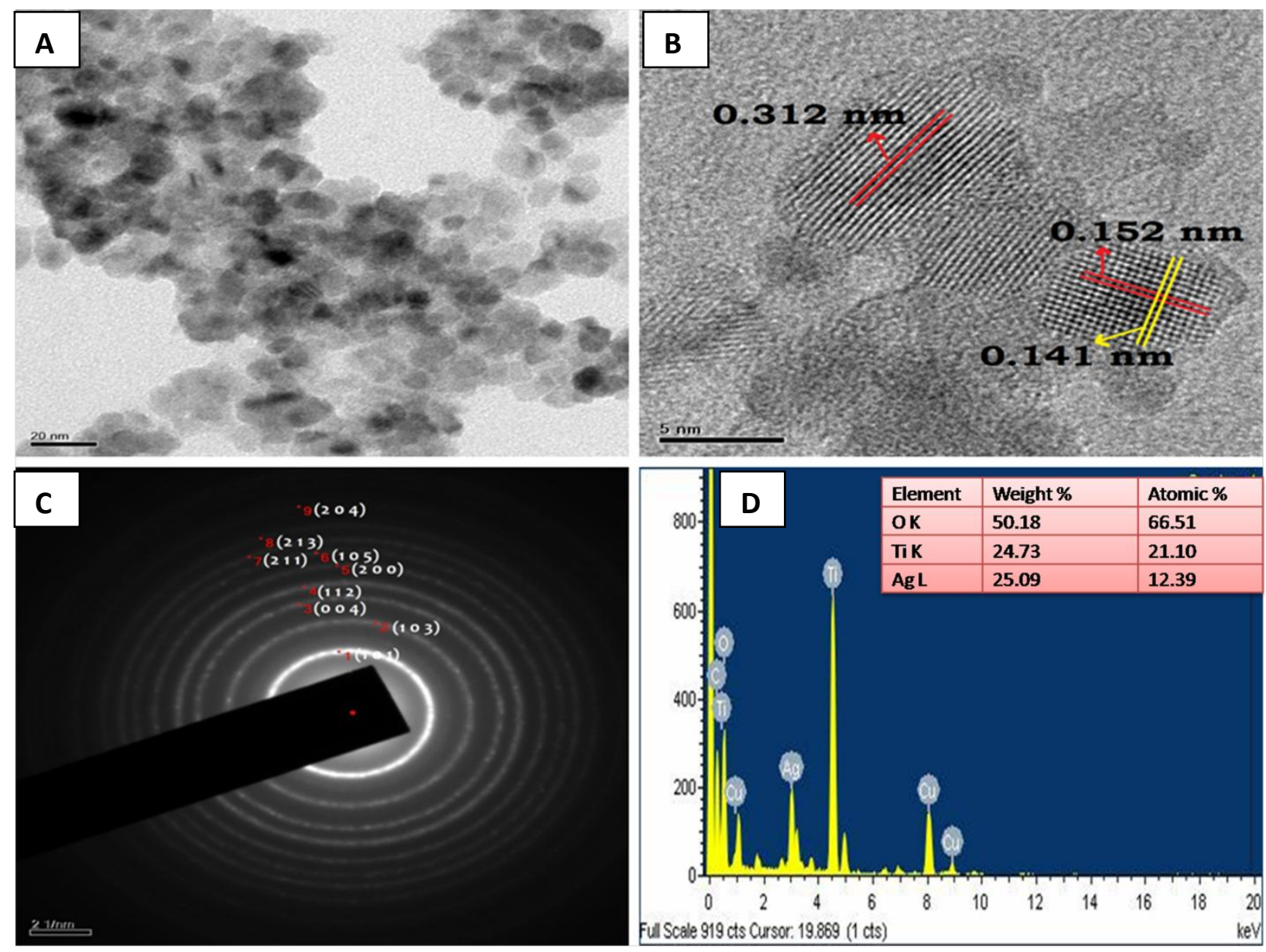
Fig. S3 TEM image of $\mathrm{Zr} / \mathrm{Ag}-\mathrm{TiO}_{2}$ nanoparticles (a), HR-TEM image shows microstructure information (b), selected area electron diffraction pattern of the doped nanoparticles (c) and EDAX profile (d) showing the elements present in the doped nanoparticles
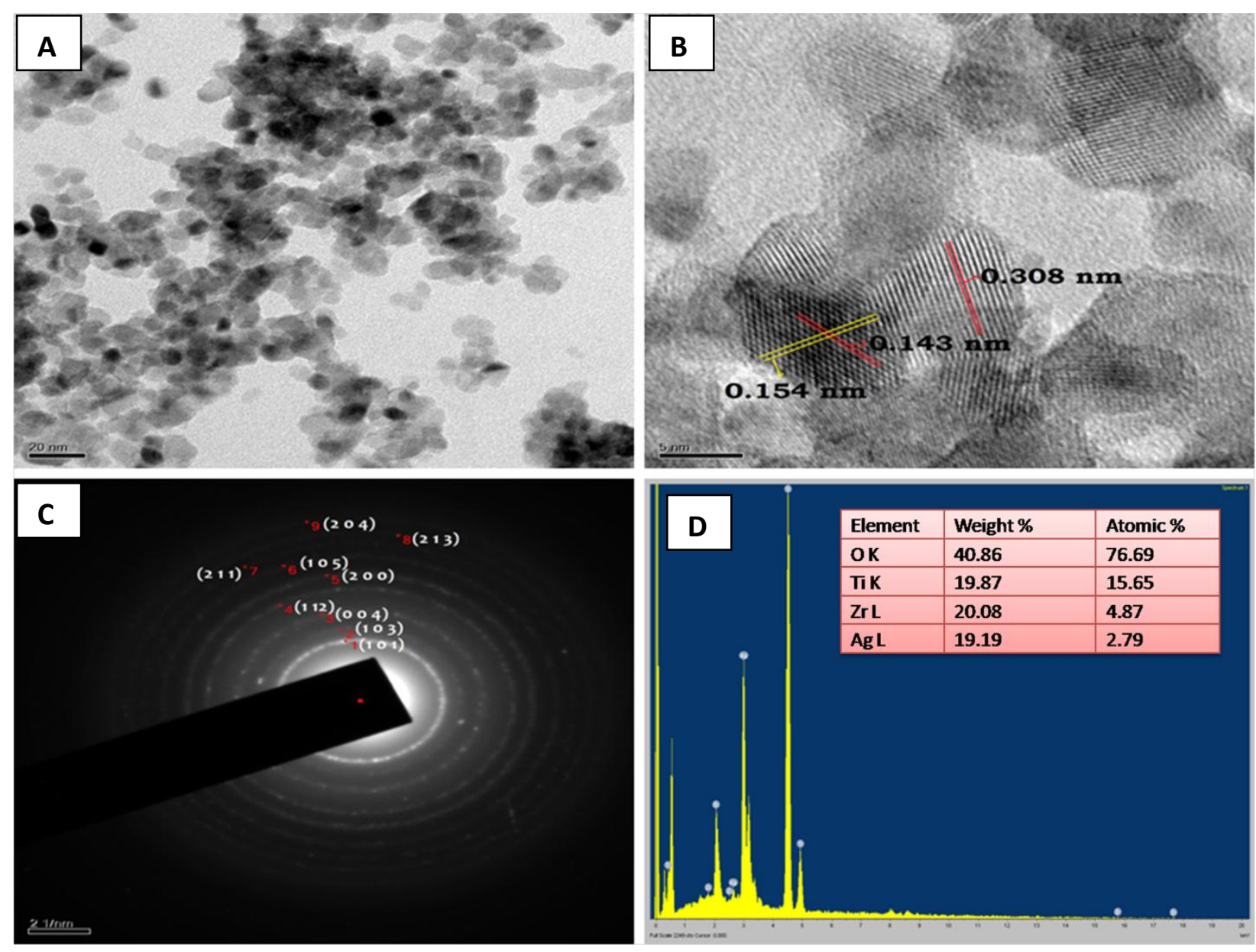
Fig. S4 LC/MS Chromatogram (a) of SMX degraded metabolites and LC/MS pattern (b, c \& d)

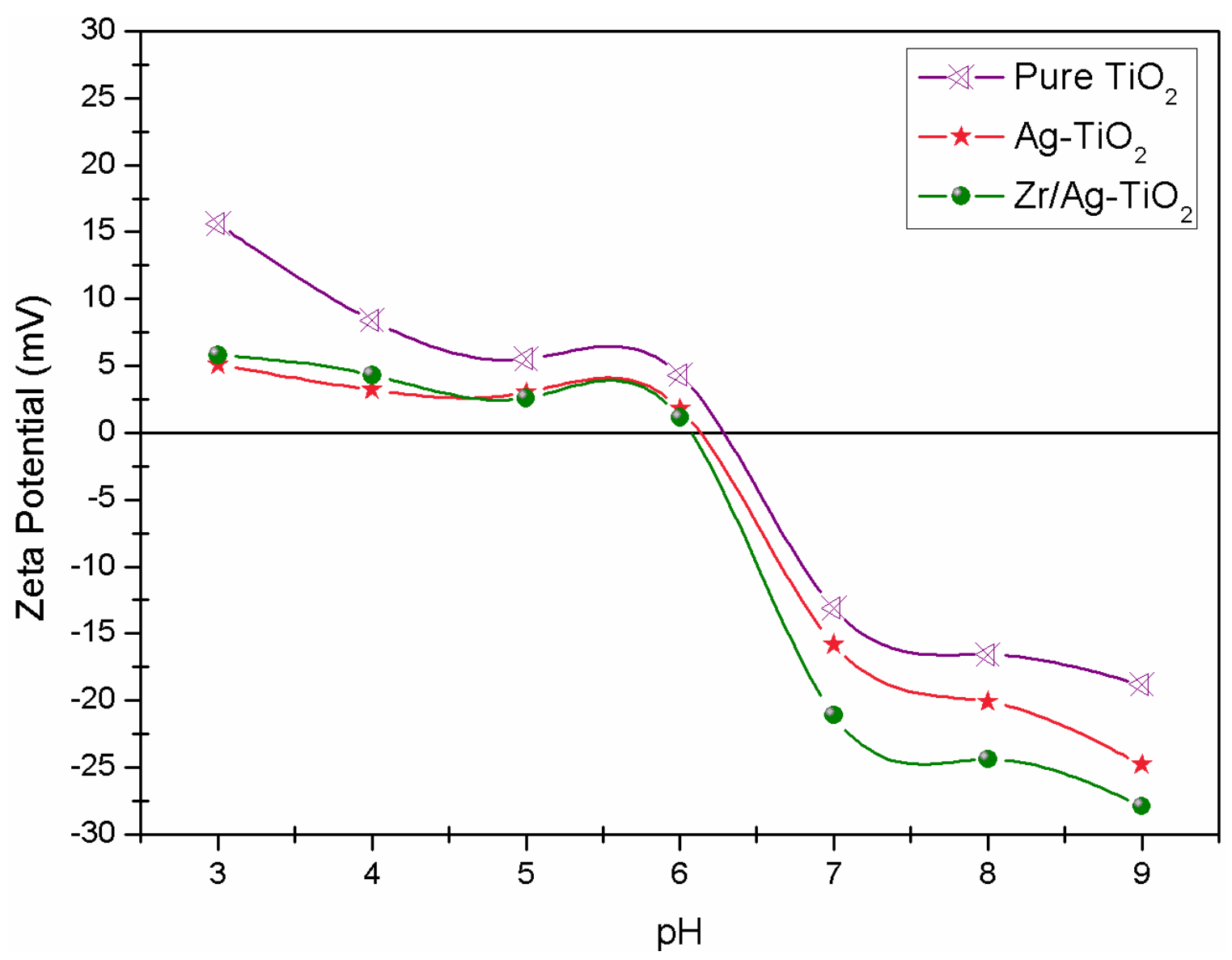


Fig. S5 LC/MS Chromatogram (a) of SMX degraded metabolites and LC/MS pattern (b, c \& d).
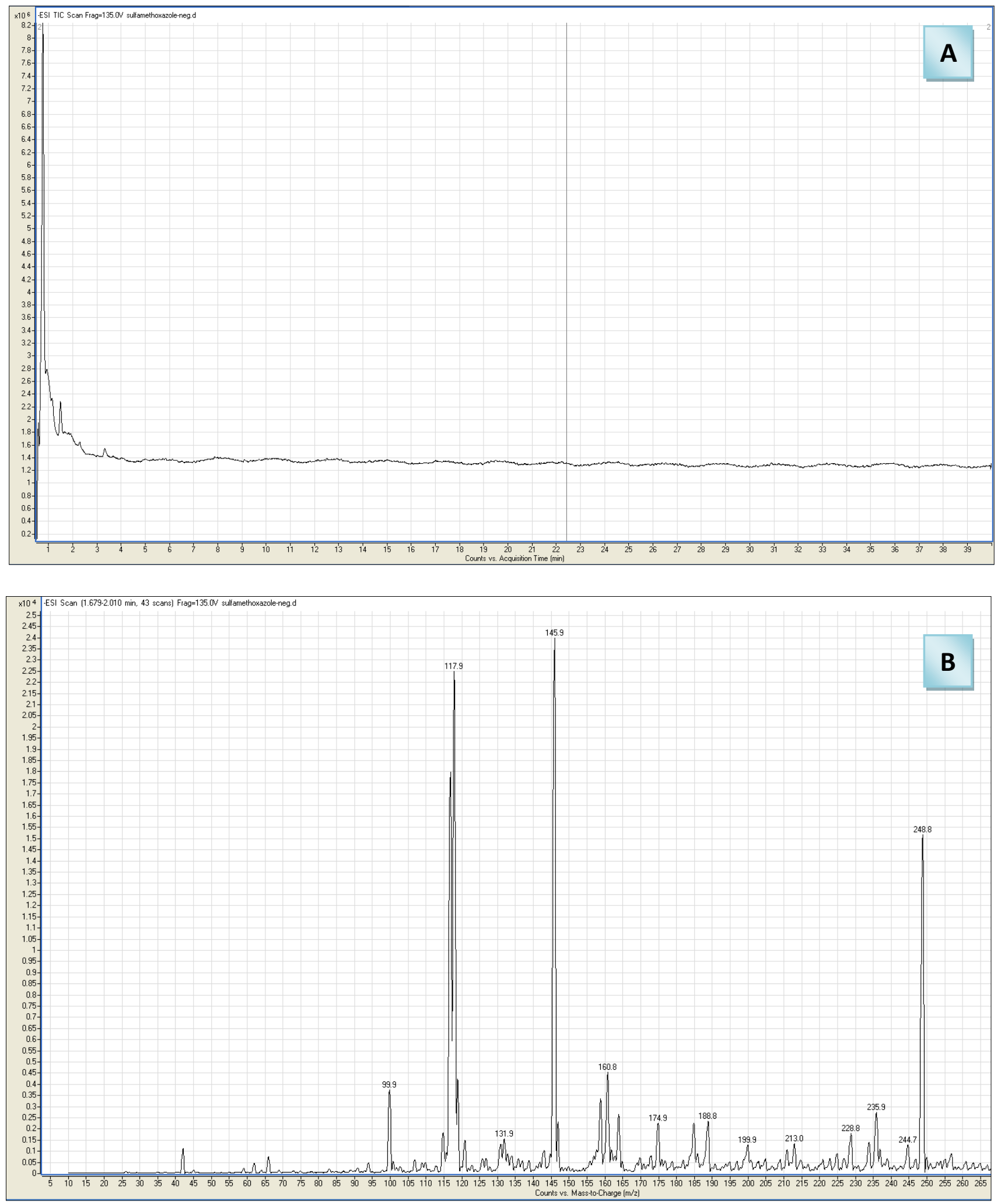

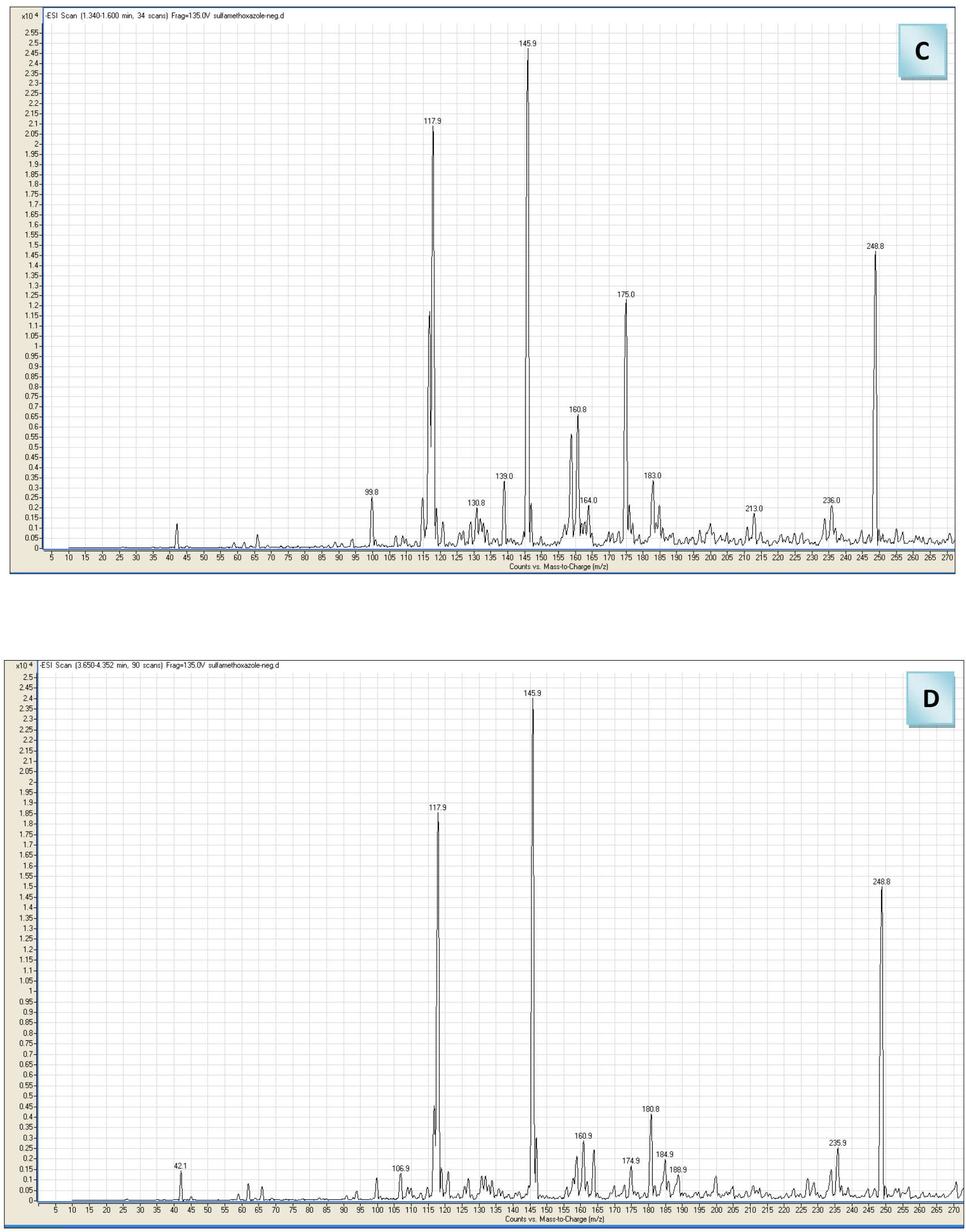
Fig. S6 Fig. S4 LC/MS Chromatogram (a) of RR-194 degraded metabolites and LC/MS pattern (b, c \& d).
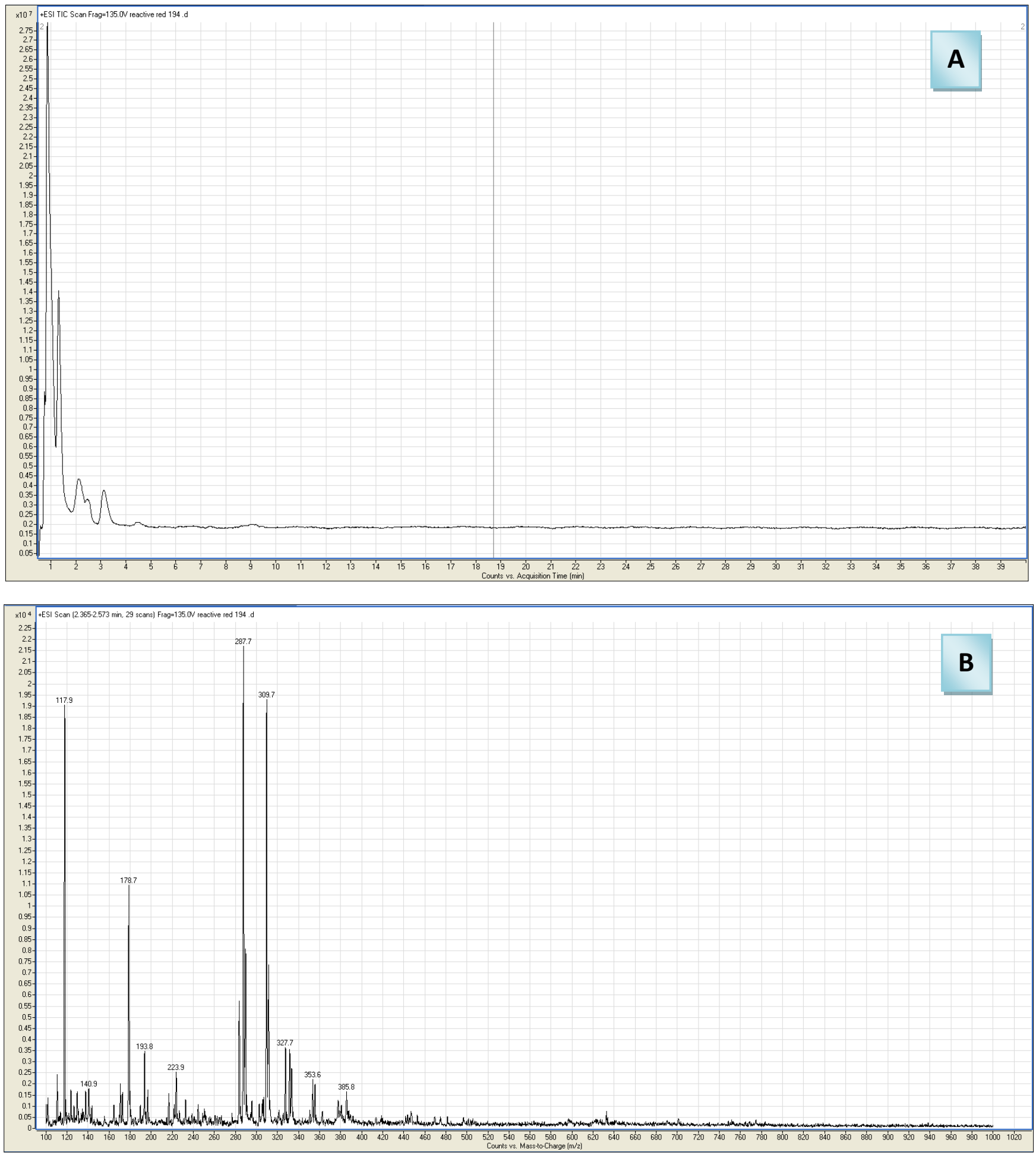

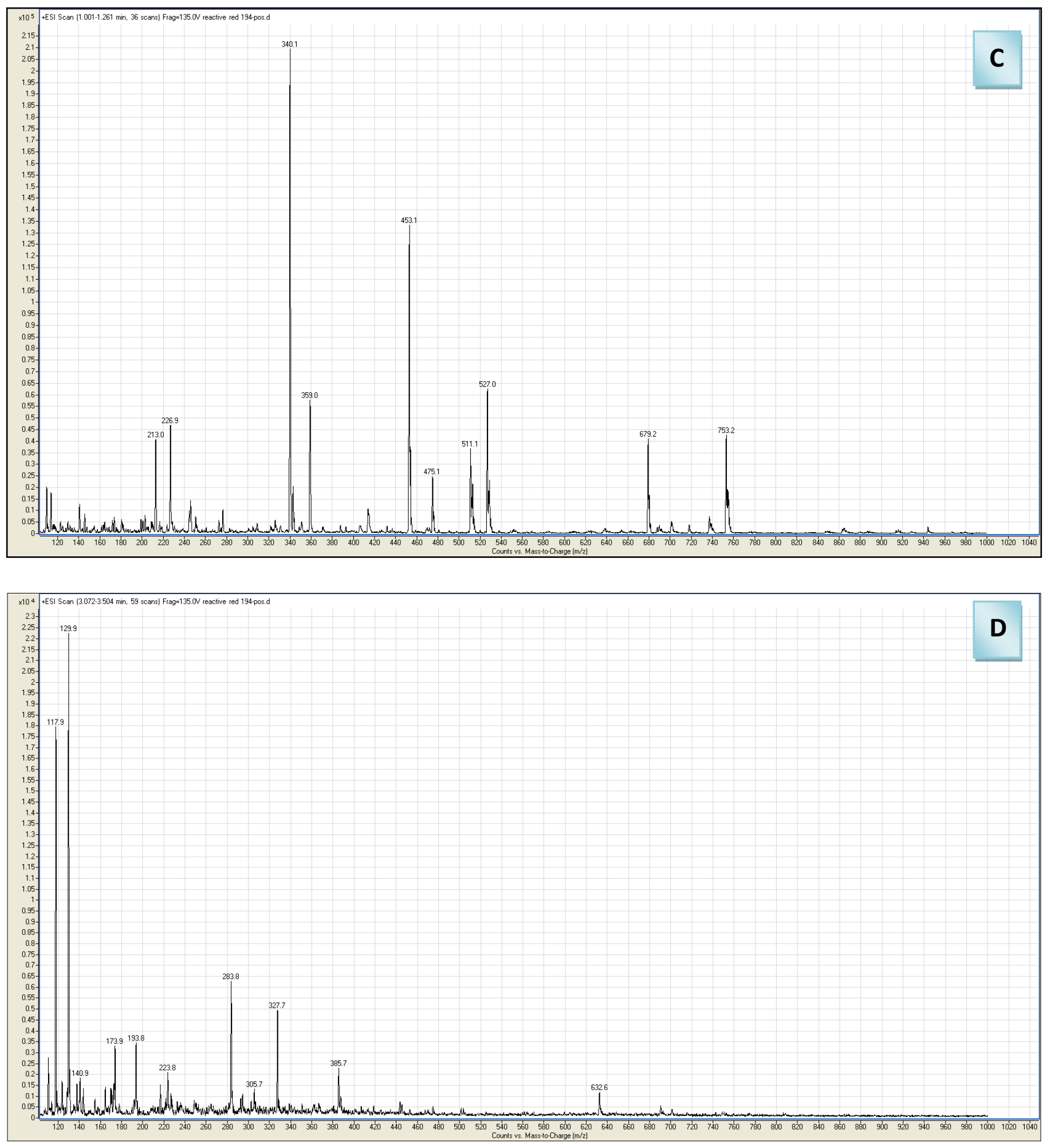
Fig.S7 Active species scavenging experiments using $\mathrm{Zr} / \mathrm{Ag}-\mathrm{TiO}_{2}$ during $\mathrm{SMX}$ (a) and RR-194 (b) degradation
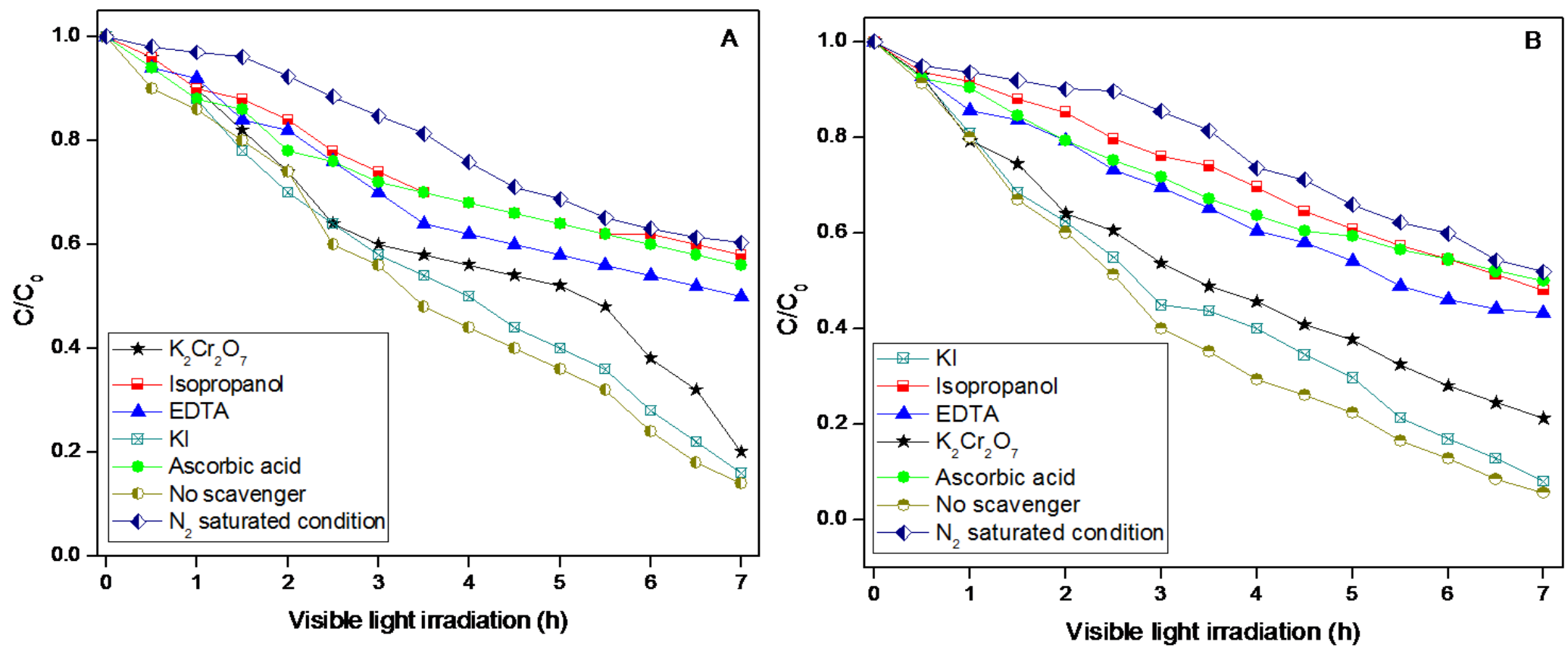
Fig.S8 Concentration of $\bullet \mathrm{OH}$ (a) and $\bullet \mathrm{O}_{2}-$ (b) radicals at different time intervals
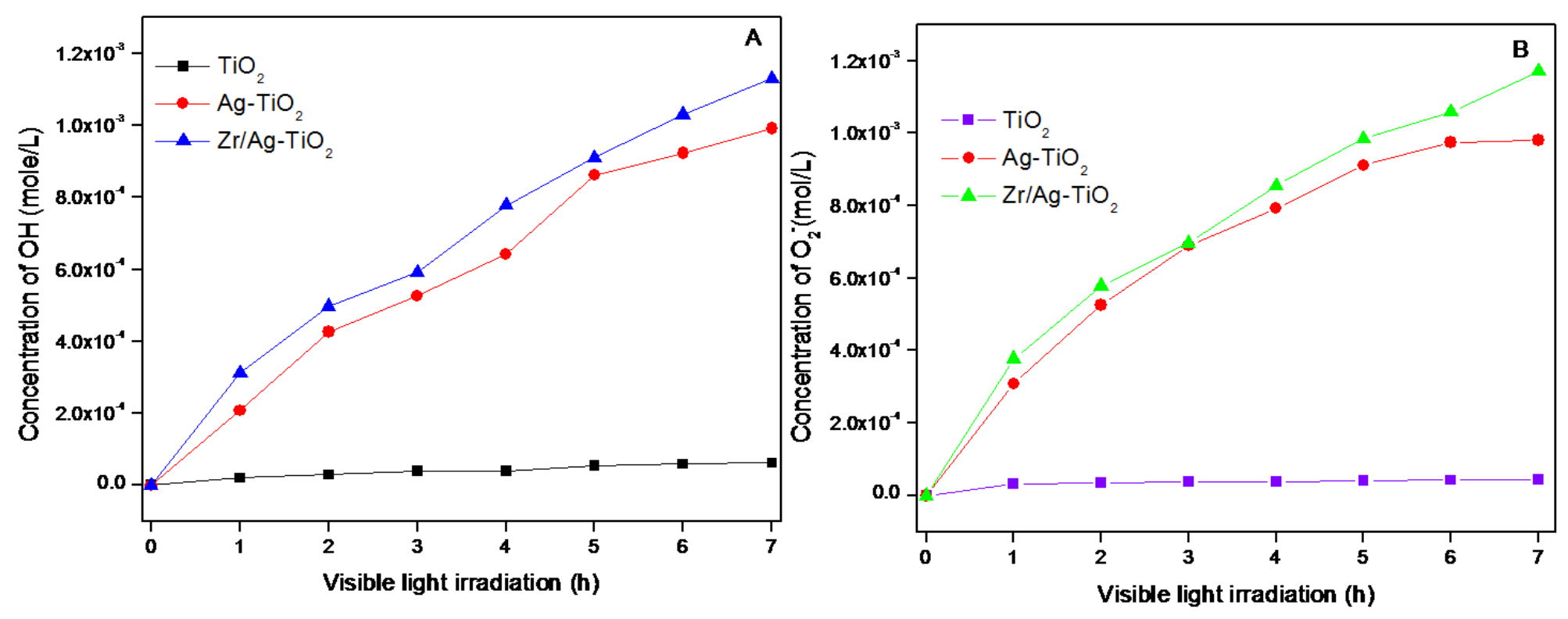
Scheme 1. Reaction pathway between NBT and superoxide radicals with the formation of formazan

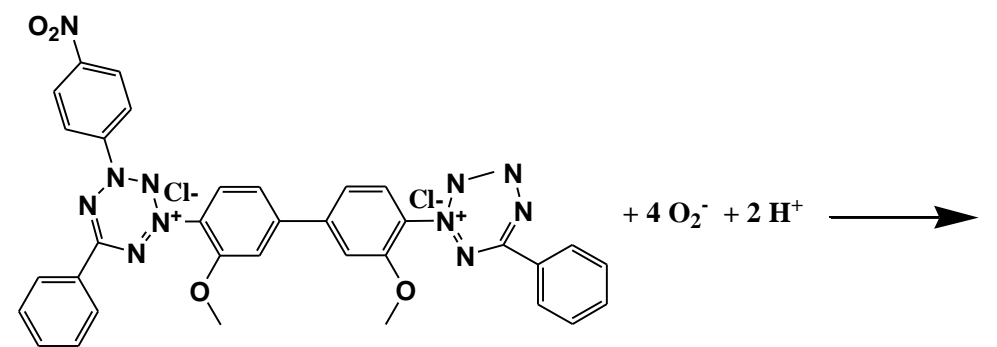

Nitroblue tetrazolium chloride

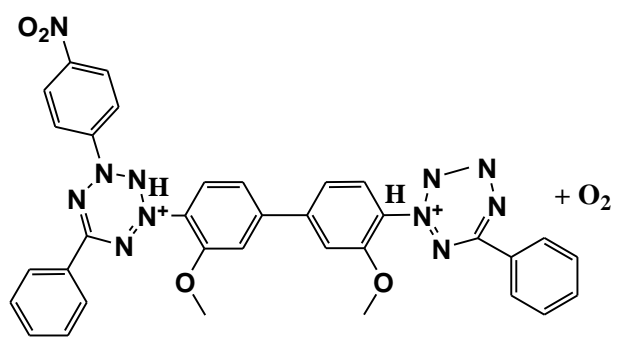

Formazan

Scheme 2. Reaction pathway between terepthalic acid and hydroxyl radical with the formation of fluorescent 2-hydroxy terepthalic acid

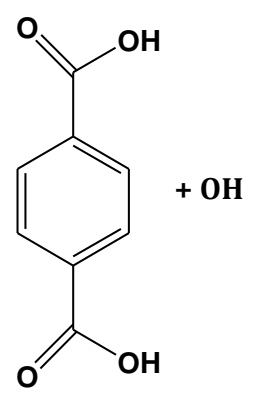

Terepthalic acid (non-flourescent)

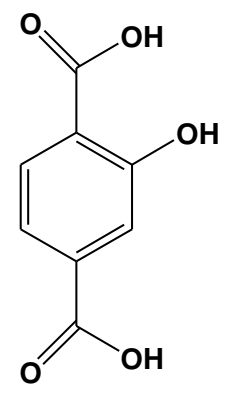

2-hydroxy terepthalic acid (flourescent) 